The Incremental Validity of the Trait Emotional Intelligence Questionnaire (TEIQue):

A Systematic Review and Meta-analysis

Andrei F., Siegling A. B., Aloe, A. M., Baldaro, B., \& Petrides, K. V. (in press). The incremental validity of the Trait Emotional Intelligence Questionnaire (TEIQue): A systematic review and meta-analysis. Journal of Personality Assessment. 


\begin{abstract}
A criticism levelled against the conceptualization of EI as a personality trait is that it overlaps considerably with the higher order personality dimensions and, therefore, has weak utility. To investigate this criticism, a systematic review and meta-analysis were conducted to synthesize the literature examining the incremental validity of the two adult self-report forms of the Trait Emotional Intelligence Questionnaire (TEIQue). Twenty-four articles, reporting 114 incremental validity analyses of the TEIQue were reviewed according to the studies' methodological features. Additionally, data from 18 studies (providing 105 effect sizes) were pooled in a meta-analysis. Results suggest that the TEIQue consistently explains incremental variance in criteria pertaining to different areas of functioning, beyond higherorder personality dimensions and other emotion-related variables. The pooled effect size was relatively small, but statistically and practically significant $\left(\Delta R^{2}=.06, S E=.0116 ; 95 \% \mathrm{CI}\right.$ : .03-.08). The number of covariates controlled for, the form of the TEIQue, and the focus on higher-order personality dimensions versus other individual-difference constructs as baseline predictors did not affect the effect size. Analyses conducted at the factor level indicated that the incremental contribution is mainly due to the Well-Being and Self-Control factors of trait EI. Methodological issues and directions for future research are discussed.
\end{abstract}

Keywords: trait emotional intelligence, TEIQue, incremental validity, personality, metaanalysis 
The Incremental Validity of the Trait Emotional Intelligence Questionnaire (TEIQue):

A Systematic Review and Meta-analysis

Researchers refer to emotional intelligence (EI) as a set of abilities or perceptions concerning the way individuals identify, make use of, deal with, and process emotions. The distinction between trait EI (or trait emotional self-efficacy) and ability EI (or cognitiveemotional ability) takes into consideration the psychometric distinction between measures of typical and maximal performance (e.g., Ackerman \& Heggestad, 1997; Cronbach, 1949), with particular emphasis on its implications for the conceptualization of emotion-related individual differences (Petrides \& Furnham, 2000, 2001). Although distinct constructs, ability and trait EI are not mutually exclusive, and their bifurcation is now widely recognized within the scientific literature (e.g., Austin, 2010; Neubauer \& Freudenthaler, 2005). However, debate persists in the field on how best to conceptualize and operationalize ability and trait EI in terms of their construct domains (e.g., Fiori, 2009; Ybarra, Kross, \& SanchezBurks, 2014).

While an expanding body of evidence keeps highlighting the importance of EI as a predictor in several domains of functioning (e.g., Malouff, Schutte, \& Thorsteinsson, 2014; Martins, Ramalho, \& Morin, 2010), many authors have ascribed to EI conceptual redundancy, questioning the overall utility of the construct (e.g., Antonakis, 2004; Conte, 2005; Harms \& Credé, 2010; Schulte, Ree, \& Caretta, 2004; Van Rooy, Alonso, \& Viswesvaran, 2005). For instance, MacCann, Matthews, Zeidner, and Roberts (2003) maintained that trait EI overlaps substantially with the Big Five and often fails to account for criterion variance over and above them, while Joseph and Newman (2010) described trait EI as an "umbrella term for a broad array of constructs that are connected only by their nonredundancy with cognitive intelligence" (p. 55). Similarly, Schlegel, Grandjean, and Scherer (2013) maintained that trait EI might be redundant with existing social and emotional 
effectiveness constructs, concluding that future research should provide evidence for its overall distinctiveness and incremental validity.

In order to address systematically concerns about the uniqueness and utility of trait EI, the present study examines evidence of criterion validity, focusing particularly on the incremental validity of one of the construct's most commonly used and comprehensive measures. The trait EI literature provides researchers with a wide range of self-report measures (for a recent review see Siegling, Petrides, \& Saklofske, 2015), showing substantial variation in their representations of the underlying construct. For this and other reasons specified in subsequent sections, the focus of the present article is exclusively on studies in which trait EI is measured through the Trait Emotional Intelligence Questionnaire (TEIQue; Petrides, 2009). Prior to this endeavour, it will be important to take a closer look at the TEIQue and its theoretical framework.

\section{Trait EI}

Trait EI represents a constellation of emotional perceptions located at the lower levels of personality hierarchies (Pérez-González \& Sanchez-Ruiz, 2014; Petrides, Pita, \& Kokkinaki, 2007). Essentially, it concerns people's perceptions of their emotional abilities comprehensively encompassing the affective aspects of personality. In order to generate an accurate representation of the personality dimensions covered by trait EI, a content analysis of prominent EI models (i.e., Bar-On, 1997; Goleman, 1995; Salovey \& Mayer, 1990) and related personality constructs, such as alexithymia, well-being, and empathy, was undertaken (Petrides \& Furnham, 2001). Only the core elements common to more than a single model of EI were retained, with singular facets unique to individual conceptualizations excluded. This systematic method gave rise to the current trait EI sampling domain, which is shown in Table 1. Trait EI theory offers a way to redefine EI models that are operationalized via self-report questionnaires in order to link them, and the measures based on them, to scientific theories of 
psychology (Petrides, 2011). Therefore, it provides an appropriate and systematic framework for the interpretation of results obtained with self-report measures of EI.

Given the conceptualization of EI as part of the major personality taxonomies, rather than as independent of them, numerous studies have examined the extent to which trait EI overlaps with the higher-order personality dimensions in the Eysenckian Giant Three (Eysenck, 1994) and Big Five (Costa \& McCrae, 1992) personality trait models. On the one hand, correlational investigations (e.g., Austin, Farrelly, Black, \& Moore, 2007; Collins, Freeman, \& Chamorro-Premuzic, 2012; Petrides et al., 2010; Van der Linden, Tsaousis, \& Petrides, 2012) and behavioural-genetic studies (Petrides, Vernon, Schermer, \& Veselka, 2011; Vernon, Villani, Schermer, \& Petrides, 2008) support the claim for inclusion of trait EI into personality hierarchies. On the other hand, the large magnitude (Cohen, 1988) of the associations between trait EI and personality dimensions, particularly Neuroticism and Extraversion, feeds into arguments about the construct's redundancy. It has indeed been maintained that trait EI does not add substantially to the prediction of psychological phenomena over the basic personality dimensions (e.g., Schulte et al., 2004). Others have attributed the predictive validity of trait EI inventories to their overlap with facets of higherorder traits relevant to the outcomes being considered (Harms \& Credé, 2010). A systematic investigation of the incremental validity of trait EI, particularly beyond higher-order personality dimensions such as the Big Five, constitutes a useful step for establishing its theoretical and practical utility.

\section{The TEIQue}

The TEIQue items were created to represent the 15 facets of trait EI, yielding roughly ten items per facet for the full form of 153 items. In contrast to many self-report measures of EI (Siegling et al., 2014), which leave much to be desired theoretically as well as 
psychometrically (Conte, 2005; Matthews, Zeidner, \& Roberts, 2004), the TEIQue is characterized by a strong theoretical and psychometric basis.

Thirteen of the 15 facets load on four oblique factors: Well-Being, Self-Control, Emotionality, and Sociability, whereas the remaining two, namely Adaptability and SelfMotivation, contribute directly to the global trait EI score, without going through any specific factor (see Table 1). Answers to the items are provided on a 7-point scale, ranging from 1 (strongly disagree) to 7 (strongly agree). The solid psychometric basis of the TEIQue instruments is reflected in the cross-cultural stability of its four-factor structure, which has been replicated in several languages (e.g., Andrei, Smith, Surcinelli, Baldaro, \& Saklofske, accepted, Italian adaptation; Freudenthaler, Neubauer, Gabler, Scherl, \& Rindermann, 2008, German adaptation; Jolić-Marjanović \& Altaras-Dimitrijević, 2014, Serbian adaptation; Martskvishvili, Arutinov, \& Mestvirishvili, 2013, Georgian adaptation; Mikolajczak, Luminet, Leroy, \& Roy, 2007, French adaptation; Petrides, 2009, English original). The full TEIQue provides scores on global trait EI, four factors, and 15 facets.

The Trait Emotional Intelligence Questionnaire-Short Form (TEIQue-SF; Petrides \& Furnham, 2006) consists of 30 items, which were taken from the full form (two per facet) and are responded to on the same 7-point Likert scale. The psychometric properties of the TEIQue-SF have been scrutinized through Item Response Theory analysis (Cooper \& Petrides, 2010). This instrument is primarily intended to measure global trait EI, although factor scores achieving the minimum standards for reliability can be derived and have been used in various studies (e.g., Arora et al., 2011). In contrast to the full form, facet scores cannot be computed from the TEIQue-SF.

A large body of literature attests to the criterion validity of the TEIQue instruments for a wide range of outcomes. For example, the measures have been linked to the use of adaptive coping strategies (Laborde, You, Dosseville, \& Salinas, 2012), symptoms of 
Borderline Personality Disorder (Sinclair \& Feigenbaum, 2012), reactions to stress (Mikolajczak, Menil, \& Luminet, 2007), and relationships satisfaction (Smith, Heaven, \& Ciarrochi, 2008). Moreover, both primary and meta-analytic studies have consistently shown that, compared to other self-report measures of EI, the TEIQue has superior psychometric properties and greater validity, including incremental validity (Di Fabio \& Saklofske 2014; Freudenthaler et al., 2008; Gardner \& Qualter, 2010; Martins et al., 2010). In a recent metaanalysis, Martins and colleagues (2010) analyzed 80 studies investigating the relationships between EI and health, and found that TEIQue was the strongest predictor of physical, psychosomatic, and mental health, compared to all other trait and ability EI measures against which it was compared. However, that meta-analysis focused on direct, rather than incremental effects (Martins et al., 2010). At the same time, emerging evidence suggests that some TEIQue facets, all of which fall under the Emotionality and Sociability factors, may actually underestimate the construct's predictive power at the global-composite level (Siegling, Petrides, \& Martskvishvili, 2014; Siegling, Vesely, \& Saklofske, 2013).

\section{Present Review: Incremental Validity of TEIQue Scores}

The often criticized overlap between trait EI and personality in combination with the lack of a systematic review or meta-analysis of the construct's incremental criterion validity provide the rationale for the present work. Incremental validity over related attributes is pivotal to the exploration of any psychological construct. Although previously conceptualized in different ways (for a review of definitions see Hunsley \& Meyer, 2003), we view incremental validity as the degree to which a measure's scores increase the accuracy of prediction of pertinent criteria, relative to other conceptually relevant predictors. Despite a growing body of research on trait EI in children and adolescents (e.g., Andrei, Mancini, Trombini, Baldaro, \& Russo, 2014; Mavroveli \& Sanchez-Ruiz, 2011; Siegling, Vesely, 
Saklofske, Frederickson, \& Petrides, accepted), our focus is on studies in which the adult forms of the TEIQue were used.

The current review was guided by two objectives: (a) to provide a systematic evaluation of the quality of studies investigating the incremental validity of the TEIQue; and (b) to provide a comprehensive quantitative account of the incremental predictive contribution of the third- (i.e., global trait EI composite) and second-order (i.e., factor) levels of the instrument. The focus was on incremental validity relative to a variety of additional predictors, including higher-order factors, lower-order constructs, and demographic variables. First, the relevant studies are reviewed with reference to their research designs, population samples, predictors other than trait EI, and criteria used. Second, a quantitative assessment of findings concerning the incremental validity of the TEIQue is conducted through a series of meta-analyses.

\section{Method}

\section{Literature Search}

The literature search was aimed at identifying studies that have explored the incremental validity of trait EI by means of the TEIQue. Two inclusion criteria were applied in order to select eligible studies: (1) focus on adult samples (18 years and older), and (2) use of the TEIQue. The literature search focused solely on empirical investigations published in peer-reviewed journals in order to maintain a high standard for the methodological rigor of the studies reviewed and to maximize the validity of conclusions drawn.

Papers were identified by conducting searches in the PsycINFO, PsycArticles, Scopus, and Web of Knowledge databases, using the following terms individually: TEIQue, TEIQue-SF, Trait Emotional Intelligence Questionnaire, and Trait Emotional Intelligence Questionnaire-Short Form. Queries were limited to human subjects and English language. An article not included at the time in electronic databases (Siegling et al., 2015) was also 
inspected. Based on these searches, which were performed in December 2014, a total of 24 articles reporting 114 analyses on the incremental validity of the TEIQue were included in the review. The article selection process is depicted in Figure 1.

In line with the study aims, the focus was on the 114 statistical analyses examining the incremental validity of the TEIQue. For this purpose, analyses performed using the TEIQue's global composite score are treated separately from those performed at the level of the four factor scores. For analyses using the global composite, results from the TEIQue and the TEIQue-SF will be integrated, as the two forms provide near-identical estimates of global trait EI (Petrides et al., 2010). Analyses performed at the factor level will be examined separately for the full and short forms because the factor scores derived from the TEIQue-SF tend to have lower reliability levels compared to those of the full form (Petrides et al., 2010). Additionally, for studies conducted at the factor level, our focus will be both on the specific contribution provided by each factor as well as on the variance explained by the four factors as a block. By including analyses conducted at the factor level in this review, we can examine the relative contributions of the four TEIQue factors in explaining incremental variance. Throughout the paper, the symbol $n$ is used to refer to subsets of the total number of analyses having specific features in common (data collected from students, focus on the Big Five, etc.).

\section{Coding of Studies}

Studies were coded by the first author for the following key features: reference information (authors and publication year), sample size and composition, study design (crosssectional, longitudinal, experimental), TEIQue form used (full vs. short), level of analysis (global vs. factor level of the TEIQue), baseline measures (personality taxonomies such as Big Five vs. isolated constructs), length of the measure used to operationalize higher-order personality dimensions (i.e., short-, medium-, and long-size scales: $\leq 10$ items, $10-60$ items, 
$>60$ items, respectively), number of predictors included in each statistical model, statistical information used to derive an effect size, and criterion variables and their domain. With respect to the last feature, in an effort to integrate research findings, criteria were clustered into the four major domains of affect, behaviour, cognition, and desires (the "ABCDs" of individual differences) and somatic health, where applicable. Regarding statistical analyses, overall, 63 analyses reported the $\Delta R^{2}$ coefficients for trait EI, with values ranging from $.02(p$ $<.01)$ for alcohol abuse (Gardner \& Qualter, 2010) to $.33(p<.01)$ for life satisfaction (Siegling et al., 2015). Statistics were converted to $\Delta R^{2}$, where possible $(n=42)$. In those cases where statistical information required to calculate an effect size was missing, study authors were contacted to provide it. In those cases where relevant information was unavailable, it was coded as missing (7\% of cases). Given the lack of information required to compute the effect size (i.e., trait EI change in $R^{2}$ ), nine analyses were discussed in the qualitative review only and were not included in the ensuing meta-analysis.

In addition, to confirm coding accuracy, $50 \%$ of the studies were fully coded by an independent rater. Across all codes, levels of inter-rater reliability were high (90-100\% agreement), and discrepancies were resolved by discussion prior to conducting the analyses.

\section{Meta-Analytic Procedure}

Our analyses were based on current and appropriate meta-analytic techniques. Both random-effects and mixed-effects models were examined. All computations were conducted in R (R Core Team, 2012). In our meta-analysis, dependence of effects occurs because multiple outcomes have been measured on the same subjects. To model this type of dependence, we relied on the method developed by Hedges, Tipton, and Johnson (2010) using the 'Robumeta' (Fisher \& Tipton, 2014) and 'Metafor' packages (Viechtbauer, 2010). Meta- regression analyses were conducted to examine differences due to study characteristics. Weighted mean effects, standard errors, $I^{2}, H$ and $R^{2}$ Meta, for moderator 
analysis (Aloe, Becker, \& Pigott, 2010) are presented for each analysis. Publication bias was formally assessed via Egger's regression test (Egger, Smith, Schneider, \& Minder, 1997) and the funnel plot (Sterne \& Egger, 2001).

Effect sizes. The trait EI change in $R^{2}\left(\Delta R^{2}\right)$, or proportion of criterion variance due to a predictor or block of predictors, was used as the effect size. The variance of each $\Delta R^{2}$ was estimated using formula 19 from Alf and Graf (1999). When studies did not directly report change in $R^{2}$, but sufficient information to estimate the semi-partial correlation was available, we used procedures developed in Aloe and Becker (2012) to estimate semi-partial correlations $\left(r_{\mathrm{sp}}\right)$, which were subsequently transformed into changes in $R^{2}$ (i.e., $\Delta R^{2}=r_{\mathrm{sp}}$ ).

\section{Results}

A summary of study characteristics and findings is shown in Tables 2 and 3.

\section{Methodology of Studies}

\section{Samples}

Sample size. Sample sizes ranged from 28 (Laborde et al., 2014) to 645 participants (Siegling et al., 2015). No study reported power calculations. Therefore, to perform a retrospective examination of the adequacy of the number of participants for each analysis, post hoc analyses for linear multiple regressions were run through the software G*Power 3.1 (Faul, Erdfelder, Buchner, \& Lang, 2009). These yield estimates of the power achieved by each analysis, given $\alpha$ error probability, sample size, number of predictors, and effect size (Faul et al., 2009). A power of .80 is conventionally deemed to be satisfactory (Cohen, 1988). Hence, analyses achieving a 1- $\beta$ error probability lower than $80 \%$ were considered to be underpowered. Results indicated that $84.2 \%$ of calculations had a power above .90 , whereas $8.8 \%$ of calculations were underpowered. With regard to the latter, in $6.1 \%$ of cases (Furnham \& Christoforou, 2007; Laborde et al., 2014; Mikolajczak, Roy, Verstrynge, \& Luminet, 2009; Petrides, Pérez-González, \& Furnham, 2007) power was in a medium range 
(i.e., $0.60-0.80$ ), whereas in $2.6 \%$ of cases it dropped below this range (Gardner \& Qualter, 2010; Mikolajczak, Menil, \& Luminet, 2007). In the remaining 7\% of cases, missing data prevented the calculation of post hoc power analyses (Mikolajczak, Luminet, et al., 2007; Mikolajczak, Luminet, \& Menil, 2006; Mikolajczak, Petrides, Coumans, \& Luminet, 2009; Petrides, Pita, et al., 2007).

Sample characteristics. Most samples reported a higher percentage of females than males (82.5\% of analyses; Chamorro-Premuzic, Bennett, \& Furnham, 2007; Furnham \& Christoforou, 2007; Furnham \& Petrides, 2003; Gardner \& Qualter, 2010; Laborde et al., 2014; Mikolajczak et al., 2006; Mikolajczak, Menil, et al., 2007; Mikolajczak, Roy, et al., 2009; Petrides, Pérez-González, et al., 2007; Petrides, Pita, et al., 2007; Siegling et al., 2015; Swami, Begum, \& Petrides, 2010; van Leeuwen, Borst, Putter, Jansen, van der Mey, \& Kaptein, 2014; Weaving, Orgeta, Orrell, \& Petrides, 2014). Moreover, with the exception of three analyses where an Indian sample was used (Singh \& Woods, 2008), participants were primarily from Western cultural backgrounds (e.g., French, English, Canadian; 97.4\%). Most analyses were performed on data collected from university students $(57.9 \%), 26.3 \%$ of analyses were performed on data collected from a general population (Andrei \& Petrides, 2013; Chamorro-Premuzic et al., 2007; Furnham \& Christoforou, 2007; Jolić-Marjanović \& Altaras-Dimitrijević, 2014; Gardner \& Qualter, 2010; Singh \& Woods, 2008), 7.9\% from specific samples (i.e., nurses, 66.7\%, Mikolajczak, Menil, et al., 2007; tennis players, 22.2\%, Laborde, Lautenbach, Allen, Herbert, \& Achtzehn, 2014; employees of a multinational company, $1.1 \%$, Siegling, Nielsen, \& Petrides, 2014; dementia caregivers, 1.1\%, Weaving et al., 2014), and 1.7\% from clinical populations (van Leeuwen et al., 2014; Uva et al., 2010). Sample characteristics were not reported in Mikolajczak, Luminet, et al. (2007).

Study designs and statistical analyses. Analyses were mainly run on data derived from cross-sectional designs $(88.6 \%)$. The remaining analyses, for which the full version of 
the TEIQue was always used, were performed on data from either experimental $(10.5 \%$; Laborde et al., 2014; Mikolajczak, Luminet, et al., 2007; Mikolajczak, Petrides, et al., 2009; Mikolajczak, Roy, et al., 2007; Mikolajczak, Roy, et al., 2009) or longitudinal (0.87\%; Uva et al., 2010) research designs.

With the exception of $1.7 \%$ of studies where ANOVA (Mikolajczak, Roy, et al., 2009) and logistic regression (Siegling et al., 2014) were employed, all analyses were performed using multiple regression models. However, effects size indicators of the incremental contribution attributable to trait EI (e.g., $\Delta R^{2}$ values) were not consistently reported across studies (see Tables 2 and 3).

Predictors. Analyses focused mainly on the global score of the TEIQue (83.3\%), and on its factor scores $(16.7 \%)$. Overall, $14.6 \%$ of analyses used higher-order personality traits as baseline predictors, of which $12.7 \%$ focused on the Giant Three (Furnham \& Christoforou, 2007; Petrides, Pita, et al., 2007) and 89.2\% on the Big Five (Chamorro-Premuzic et al., 2007; Furnham \& Petrides 2003; Jolić-Marjanović \& Altaras-Dimitrijević, 2014; Mikolajczak, Menil, et al., 2007; Mikolajczak, Petrides, et al., 2009; Mikolajczak, Roy, et al., 2007; Petrides, Pérez-González, et al., 2007; Petrides, Pita, et al., 2007; Sanchez-Ruiz, Mavroveli, \& Poullis, 2013; Siegling et al., 2015; Singh \& Woods, 2008). The remaining $35.1 \%$ of analyses were performed using lower-order personality constructs, such as optimism and social desirability (e.g., Mikolajczak, Menil, et al., 2007), or other variables, like body-mass index (Swami et al., 2010), and cognitive ability (Siegling et al., 2014) as baseline predictors.

Measures. Trait EI was measured via the current full TEIQue form in $71.05 \%$ of analyses (Gardner \& Qualter, 2010; Jolić-Marjanović \& Altaras-Dimitrijević, 2014; Mikolajczak, Luminet, et al., 2007; Mikolajczak, Petrides, et al., 2009; Mikolajczak, Roy, et al., 2007; Petrides, Pita, et al., 2007; Petrides, Pérez-González, et al., 2007; Uva et al., 2010), 
while in $1.7 \%$ of studies, an earlier edition of the TEIQue full form, comprising 144 items, was used (Petrides, Pita, et al., 2007; Petrides, Pérez-González, et al., 2007). Analyses were conducted at the factor level in $12.5 \%$ of cases (Freudenthaler et al., 2008; Mikolajczak et al., 2006; Mikolajczak, Luminet, et al., 2007; Mikolajczak, Roy, et al., 2009). Baseline predictors were operationalized through self-report, with the exception of emotion regulation, which was measured by means of biological markers (Laborde et al., 2014), and body-mass index, which was computed as $\mathrm{kg} / \mathrm{m}^{2}$ based on self-reported height and weight (Swami et al., 2010).

With respect to the Big Five, where analyses were conducted at the global level of the TEIQue, short- to medium-size scales (10-60 items) were preferred (59\%). In $55.5 \%$ of these analyses, scores derived from the full form were employed. Where longer questionnaires to assess the Big Five were adopted, trait EI was always assessed through the full form of the TEIQue (32.8\%; Petrides, Pita, et al., 2007; Petrides, Pérez-González, et al., 2007). Inventories assessing the Big Five generally comprised short statements, while singleword items (i.e., adjectives) were the preferred item format in $21.3 \%$ of cases (Mikolajczak, Menil, et al., 2007; Mikolajczak, Petrides, et al., 2009; Mikolajczak, Roy, et al., 2007; Siegling et al., 2015). Likert-type rating scales were always used as the preferred response format. Regarding the Giant Three, the Eysenck Personality Questionnaire (EPQ, Eysenck \& Eysenck, 1975) was employed, either in its 90- (33.33\% of analyses; Furnham \& Christoforou, 2007) or 84-item (66.66\% of analyses; Petrides, Pita et al., 2007) versions. Regarding analyses at the factor level of the TEIQue, the Big Five were assessed by means of short questionnaires only (Freudenthaler et al., 2008; Mikolajczak, Luminet, et al., 2007; Mikolajczak, Roy, et al., 2009). In these cases, the full form of the TEIQue was used $46.1 \%$ of times, whereas the TEIQue-SF 53.9\% of times (Siegling et al., 2015). The Big Five were 
measured via the Big Five Mini-Markers scale (Saucier, 1994), which comprises adjectivebased items (Siegling et al., 2015), in 30.8\% of times.

With respect to measures of other predictors, only when the Positive Affect and Negative Affect Scale (PANAS; Watson, Clark, \& Tellegen, 1988) was used (13.2\% of cases) were items presented in the form of single adjectives (Andrei \& Petrides, 2013; Mikolajczak, Petrides, et al., 2009; Petrides, Pérez-González, et al., 2007; Uva et al., 2010). When social desirability was included as a predictor (2.6\% of cases), a dichotomous response format (i.e., true/false) was employed (Mikolajczak, Petrides, et al., 2009; Mikolajczak, Roy, et al., 2007). The remaining questionnaires used short statements as item structure combined with a Likert-type response format. In the two analyses where cognitive ability was controlled for, different maximum-performance measures were used, i.e., the Baddeley Reasoning Test (Sanchez-Ruiz et al., 2013) and an in-house Wonderlic-type test (Siegling et al., 2014).

Criteria. Most analyses were performed on criteria from the domain of affect (48.2\%), such as burnout, anxiety, and depression. Behavioural criteria, like alcohol abuse and eating disorders, were employed in $10.5 \%$ of cases (Gardner \& Qualter, 2010; Laborde et al., 2014; Petrides, Pérez-González, et al., 2007), whereas another 10.5\% of analyses focused on cognitive criteria, like academic achievement and job/life satisfaction (Freudenthaler et al., 2008; Mikolajczak, Luminet, et al., 2007; Sanchez-Ruiz et al., 2013; Siegling et al., 2015; Sigh \& Woods, 2008). Only $1.7 \%$ of analyses used desires as criteria, specifically craving (Uva et al., 2010) and sensation seeking (Furnham \& Christoforou, 2007). Outcomes pertaining to somatic health were explored in 5.3\% of cases (Freudenthaler et al., 2008; Mikolajczak et al., 2006). The remaining $23.7 \%$ of analyses focused on multifaceted criteria spanning two or more domains, such as personality disorders, leadership, and body image. 
Measures. Most criteria were questionnaire-based (93.9\%) having a similar item structure and response format to the TEIQue (i.e., Likert-type). An adjective-based measure, the PANAS, was used in 3.5\% of cases (Mikolajczak, Petrides, et al., 2009; Mikolajczak, Roy, et al., 2007), and a dichotomous response format was used with measures of alcohol abuse (1.7\% of cases; Gardner \& Qualter, 2010) and personality disorders (7.9\% of cases; Petrides, Pérez-González, et al., 2007).

Alternative measurement methods were employed in $6.1 \%$ of cases. For $28.6 \%$ of these cases, a physiological index of reaction to stress (Mikolajczak, Roy, et al., 2007) and emotion regulation (Laborde et al., 2014) was employed, viz., cortisol secretion. Reaction to stress was also conceptualized as attention deployment and measured through a visual task (14.1\% of cases; Mikolajczak, Roy, et al., 2009). Regarding behavioural criteria, performance under stress was operationalized through recording the number of errors in a sport task (14.1\% of cases; Laborde et al., 2014). With respect to cognitive criteria, academic performance was operationalized as GPA scores derived from academic records $(14.1 \%$ of cases; Sanchez-Ruiz et al., 2013). Leadership status was obtained from the human resources department of the participating company (14.1\% of cases; Siegling et al., 2014). Last, actual/ideal weight discrepancy was computed by subtracting self-reported actual from selfreported ideal weight (14.1\% of cases; Swami et al., 2010).

\section{Summary of Study Findings}

TEIQue scores predicted or explained incremental criterion variance in $84.2 \%$ of analyses. For analyses performed at the level of the global score, significant effects were observed in $81 \%$ of cases. The analyses investigating the incremental validity of the four trait EI factors controlling for higher-order personality dimensions (11\%), consistently reported significant results for both forms of the TEIQue (100\% of cases; Freudenthaler et al., 2008; Mikolajczak, Luminet, et al., 2007; Mikolajczak, Roy, et al., 2009; Siegling et al., 2015). 
The effects were due to the factors of Well-Being (53.8\% of cases; Siegling et al., 2015), Self-Control (30.8\% of cases; Mikolajczak, Luminet, et al., 2007; Mikolajczak, Roy, et al., 2009; Siegling et al., 2015), and Emotionality (7.7\% of cases; Siegling et al., 2015), while $30.8 \%$ of analyses did not specify the unique contribution of each factor (Freudenthaler et al., 2008). Results from the analyses focusing on predictors other than higher-order personality traits consistently revealed significant incremental contributions of the TEIQue factors (100\%; Mikolajczak et al., 2006; Swami et al., 2010). Significant effects were attributable to Self-Control (66.7\% of cases; Mikolajczak et al., 2006), Well-Being (50\% of cases), and Sociability (16.7\% of cases; Mikolajczak et al., 2006).

Main analysis. The 18 studies available for meta-analysis included a total of 23 independent samples $(\mathrm{N}=4404)$ and 105 effect sizes. The change in $R^{2}$ for trait EI ranged from .00 to .33 with a median of .04 , and showed a slightly positively skewed distribution. Specifically, $\Delta R^{2}$ values were generally small, as they ranged from .00 to .10 in $78.3 \%$ of analyses. In $19.1 \%$ of cases, the effect-size was medium (between .10 and .25), and in $1.9 \%$ of analyses it was large (above .25). Considering that in many studies multiple variables were measured on the same sample and that several effect size estimates were associated with each study (i.e., the estimates were not statistically independent; Hedges et al., 2010), dependence of effects may have occurred. For this reason, we performed an overall analysis using Hedges and colleagues' (2010) robust standard errors to account for the dependence of effects. As shown in Table 4, the overall weighted average change in $R^{2}$ was .06 ( $S E=$ .0116 ), with a $95 \%$ CI from .03 to .08, under the random-effects model. There was a moderate degree of heterogeneity across samples $\left(\tau^{2}=.0016, I^{2}=39.3 \%, p<.01\right)$, which was expected given their methodological diversity (Higgins, Thompson, Deeks, \& Altman, 2003).

Moderator analysis. To examine differences due to study characteristics, metaregression analyses were performed. The following potential moderators were fitted 
separately: sample composition, study design (cross-sectional, longitudinal, experimental), form of the TEIQue used (full vs. short), level of analysis for trait EI (global vs. factor level of the TEIQue), predictors (personality only, other variables only, personality and other variables together), focus on higher-order personality dimensions (Big Five vs. Giant Three), length of the measure used to assess higher-order personality dimensions (short-, medium-, long-size scales; $\leq 10$ items, $10-60$ items, $>60$ items respectively), and number of predictors included in each statistical model. Given the limited number of studies per criterion, analyses were not conducted separately for each $\mathrm{ABCD}$ domain. Instead, criterion domain (i.e., affect, behaviour, cognition, desires and somatic health) was modelled as a moderator. Although we tested for nine potential moderators, we discuss below only one that explained significant variability among effect sizes (see Table 4).

Length of higher-order personality questionnaires. Three categories were included in this variable (long, $k=25$, medium, $k=8$, and short, $k=39$ ). The length of the questionnaire used to assess higher-order personality dimensions relates significantly to the size of the change in $R^{2}$ under the mixed-effects model, with studies using a short personality inventory reporting the largest change in $R^{2}$ and studies where a long questionnaire was employed reporting the smallest change in $R^{2}$. Overall, this moderator explained $75 \%$ of the between-studies variability.

Publication bias. Publication bias occurs because statistically significant results are more likely to be published than non-significant results. For the scatter plot, the study effect sizes were plotted against a measure of study size or precision. In the absence of publication bias, the plot is expected to look like a symmetrical inverted funnel, centered on the summary effect, while the intercept of the Egger's regression test should not significantly differ from zero. A statistically significant intercept provides evidence of funnel plot asymmetry, namely, for the presence of publication bias. Results from both the Egger's regression test 
and the funnel plot indicated that there were statistically significant asymmetries $(z=4.78, p$ $<.001$, and Figure 2). Accordingly, these results should be interpreted with some caution, as they may overestimate the underlying effects.

\section{Discussion}

This is the first systematic review and meta-analysis of the incremental validity of trait EI as operationalized through the TEIQue. To our knowledge, it is also the first metaanalysis on incremental validity in the field of EI more generally. We systematically identified and reviewed 24 articles covering a wide range of criteria, which were either primarily related to one of the ABCDs (i.e., affect, behaviour, cognition and desire) of individual differences or had a mixed conceptual core. Trait EI emerged as a statistically and practically significant incremental predictor of multiple psychological variables beyond the higher-order personality dimensions (i.e., the Big Five or the Giant Three) and specific individual difference variables (e.g., alexithymia and social desirability). The overall metaanalytic effect size was .06.

Given the criticisms surrounding trait EI (e.g., Antonakis, 2004; Conte, 2005; Harms \& Credé, 2010; Schulte et al., 2004; Schlegel et al., 2013; Van Rooy et al., 2005), it was imperative to enrich the literature of the field by systematically investigating the extent to which the construct has incremental predictive utility. Although small, the overall effect-size confirms the distinctiveness and theoretical importance of trait EI.

In most cases, controlling for the influence of other predictors did not nullify the TEIQue's associations with the criteria. Indeed, around $80 \%$ of the 114 incremental validity analyses performed across the various studies yielded statistically significant effects. While the pattern of these effects appeared inconsistent across psychological domains (i.e., affect, behaviour, cognition, desire and somatic health), it did not reach significance when modelled as a potential moderator. The fact that the TEIQue predicted $94 \%$ (43 out of 47) of the 
criteria within the domain of affect is in line with the theoretical nature of trait EI, which is primarily expected to predict phenomena related to individuals' emotional experience. For the same reason, trait EI can be expected to exert incremental predictive effects on behavioural variables with an affective basis, such as facial recognition of emotional expressions (Petrides \& Furnham, 2003).

Even though the TEIQue has a multi-factorial structure, the majority of studies reviewed here focused on the global level. Our review showed that, at the factor level, the predictive power of trait EI appears to be mostly due to its Well-Being and Self-Control factors, which tended to be the strongest incremental predictors in both the full and the short forms (Mikolajczak et al., 2006; Mikolajczak, Luminet, et al., 2007; Mikolajczak, Roy, et al., 2009; Siegling et al., 2015; Swami et al., 2010). This finding is consistent with emerging evidence suggesting that some trait EI facets included under the Emotionality and Sociability factors may compromise the construct's predictive power at the global composite level (Siegling, Petrides, \& Martskvishvili, 2015; Siegling et al., 2013).

The results of our meta-analysis revealed that the incremental validity of the TEIQue remains significant, irrespective of baseline predictors. These findings further highlight the unique contribution of trait EI in explaining the variance of construct-relevant criteria. Of the 74 analyses focusing on higher-order personality dimensions, more than $80 \%$ reported a significant incremental contribution for trait EI. Where the Big Five were concerned, significant contributions for trait EI were found for $89 \%$ of the affective criteria, $33 \%$ of the behavioural criteria, and $100 \%$ of the cognitive criteria (no criterion pertained to the domain of desire). Overall, the percentage of significant results was slightly higher if either short or medium-size scales were used to assess the Big Five, compared to long scales, as attested by the moderator analyses we performed. This issue should be considered by future studies addressing the incremental validity of trait EI, at least as far as the TEIQue is concerned. 
As previously noted (Freudenthaler et al., 2008; Petrides, Pérez-González, et al., 2007), we need to consider that the incremental validity analyses of trait EI at the global level against either the Giant Three or the Big Five are inherently biased. While personality constructs comprise three or five different variables, trait EI at the global level represents only one. Based on this statistical advantage alone, higher-order personality dimensions are much more likely than trait EI to be significantly associated with criterion variables. Keeping this statistical artifact in mind, it is possible that the real-world implications of trait EI are underestimated in many studies, unless the analyses are adjusted for unequal degrees of freedom.

The present review reveals that the TEIQue shows solid incremental validity in the presence of other individual differences constructs, including cognitive ability, the basic dimensions of mood (i.e., positive and negative affectivity), alexithymia, and the higher-order dimensions of personality. Previous research has shown that the full form of the TEIQue demonstrated superior incremental validity compared to other trait EI scales (Gardner \& Qualter, 2010), even when the effects of the Big Five were controlled for (Freudenthaler et al., 2008).

Our review indicates that little interest has been directed toward cognitive abilities as baseline predictors over which to investigate incremental validity. Indeed, only two analyses in this review used cognitive ability as a baseline predictor (Sanchez-Ruiz et al., 2013; Siegling, Nielsen, et al., 2014). The reason why IQ has been used in so few studies can be found in trait EI theory, which sees the construct as part of the realm of personality and, therefore, unrelated to cognitive abilities, as has been repeatedly confirmed in the literature (e.g., Andrei et al., 2014; Ferguson \& Austin, 2010; Mikolajczak, Luminet, et al., 2007). 
Several specific methodological features of the reviewed studies should be considered when interpreting the results. Some concerns can be raised about sample compositions. Despite a substantial number of analyses conducted on data from the general population, most $(61 \%)$ were based on university students in Western countries, who tend to be disproportionately healthy, young, and female. This should be taken into account when drawing conclusions from this review about the incremental validity of the TEIQue and of trait EI, more generally. If the interest lies in a particular group (e.g., adults in the workforce), results of studies using relevant samples should be examined separately. The tables presented in this review should serve as a useful starting point for this purpose.

With respect to measures, data came from the same source and were based on the same method. Predictor and criterion scores were consistently self-reported by participants, possibly resulting in common-method variance effects (e.g., through mood states). Although there is evidence that trait EI can incrementally predict objectively assessed phenomena (Mikolajczak, Roy, et al., 2007; Siegling, Nielsen, et al., 2014), the existing literature clearly over-relies on self-report questionnaires. That said, many psychological criteria of prime importance are subjective and can only be measured via self-report (e.g., life satisfaction).

Even though $70 \%$ of analyses in this review controlled for the effects of either the Giant Three or the Big Five, only 39\% of them operationalized personality through long inventories (Petrides, Pérez-González, et al., 2007; Petrides, Pita, et al., 2007; Furnham \& Christoforou, 2007). The greatest concern with short measures of the Big Five resides in their lower level of predictive validity (Credé, Harms, Niehorster, \& Gaye-Valentine, 2012), which leads to potential bias when they are used as controls in incremental validity analyses. Nonetheless, results from this review showed a consistent pattern of incremental prediction for trait EI, irrespective of the length of baseline measures. 
Another issue pertains to the conceptual overlap between TEIQue facets and criteria (Zeidner, Matthews, \& Roberts, 2012). Although the TEIQue's incremental contribution in outcomes like happiness may reflect substantial overlap between its content and the criterion (e.g., TEIQue Well-Being includes a facet of trait happiness), the instrument has been examined as a predictor of various criteria, such as actual-ideal weight discrepancy (Swami et al., 2010) and academic performance (Sanchez-Ruiz et al., 2013), that are conceptually and operationally orthogonal to it. Overall, however, criteria non-overlapping with trait EI in terms of either conceptual content or measurement format were used in only $6 \%$ of the analyses reviewed.

\section{Limitations}

A limitation of the present work is that it does not include unpublished material and, therefore, it is likely affected by publication bias, which reflects the tendency for significant results to be published more frequently than non-significant results (Rosenthal, 1979). The inclination to avoid publishing null results is a prevalent issue in the psychological literature (for a comprehensive discussion of publication bias problems in psychology, see, e.g., Ferguson \& Heene, 2012). In that respect, the present results may represent an overestimation of the incremental explanatory effects of trait EI.

Another potential limitation concerns the plethora of variables that have been examined as criteria for trait EI. Several of these variables may not be theoretically relevant, but were nevertheless examined as criteria within the stream of research aimed at exploring the effects of a popular construct. For example, criteria such as attention deployment, eating disorders, craving, and sensation seeking are not conceptually proximal to trait EI. Had we explicitly focused on theoretically relevant criteria, the effect sizes observed would have been considerably higher. 
The present review should be considered in light of its restricted focus on studies using adult samples. Nevertheless, growing evidence attests to the incremental validity of the adolescent TEIQue form beyond various baseline constructs, including the Big Five and coping styles (e.g., Andrei et al., 2014; Mavroveli \& Sanchez-Ruiz, 2011; Siegling et al., 2015).

\section{Implications for Future Research}

Several specific directions for future research can be outlined. Although most studies possessed sufficient statistical power and demonstrated the incremental validity of the TEIQue, a priori power calculations and values for incremental validity coefficients (e.g., $\Delta R^{2}$ ) should be computed and reported more systematically. In addition, future studies are urged to address the problem of common-method biases by integrating data from different sources, such as family members, peers, and colleagues, and using objective outcome measures, particularly for behavioural criteria, such as aggression. Common-method variance would have served artificially to attenuate or inflate the observed relationships (Podsakoff, MacKenzie, Lee, \& Podsakoff, 2003), thus creating a need for new research simultaneously considering both procedural and statistical remedies.

Further directions for assessing the predictive utility of the TEIQue should look to new study populations and settings. Although a considerable proportion of research has focused on non-student samples and has been conducted in real-life contexts, it would be desirable to expand the types of samples and settings, while simultaneously aiming to remedy the other limitations discussed in this review. Particularly worthwhile would be studies conducted in ecologically valid contexts, on diverse sets of samples, and seeking to avoid common-method and common-source biases. For instance, there exist few studies that are conducted outside the laboratory and that are based on non-student samples using methodologically diverse measures for predictors and criteria. 
Future investigations should also aim to expand our understanding of the relative utility of the 15 trait EI facets. Indeed, this review showed that the bulk of trait EI effects were mainly due to its intrapersonal-oriented factors, viz., Well-Being and Self-Control. Perhaps, not all of the TEIQue facets contribute equally to the predictive utility of the total composite (Siegling, Petrides, et al., 2015). At the same time, even though Sociability and Emotionality did not emerge as strong predictors in our meta-analysis, it is reasonable to expect that they will assume salience when examined in relation to criteria that are more social in nature.

\section{Concluding Remarks}

The qualitative and quantitative results of the present review suggest that trait EI is a key individual differences construct, putting to rest the assertion that it is redundant with basic personality dimensions. An umbrella construct comprehensively encompassing the emotion-related aspects of personality allows for easier prediction of domain-coherent criteria as well as for straightforward explanations of their variance, which would otherwise require awkward combinations of the Big Five personality factors. Even though certain methodological patterns across the studies reviewed may impose limitations to the generalizability of the results, the confident conclusion is that trait EI reliably accounts for substantial variation in a wide range of criteria that is not accounted for by other constructs. 


\section{References}

References marked with an asterisk indicate studies included in the systematic review.

References marked with two asterisks indicate studies included in the systematic review and in the meta-analysis.

Ackerman, P. L., \& Heggestad, E. D. (1997). Intelligence, personality, and interests: evidence for overlapping traits. Psychological Bulletin, 121, 219-245. doi: 10.1037//00332909.121.2.219

Alf, E. F., \& Graf, R. G. (1999). Asymptotic confidence limits for the difference between two squared multiple correlations: A simplified approach. Psychological Methods, 4, 7075. doi: 10.1037/1082-989X.4.1.70

Aloe, A. M., \& Becker, B. J. (2012). An effect size for regression predictors in meta-analysis. Journal of Educational and Behavioral Statistics, 37, 278-297. doi:

\section{$10.3102 / 1076998610396901$}

Aloe, A. M., Becker, B. J., \& Pigott, T. (2010). An alternative to $R^{2}$ for assessing linear models of effect size. Research Synthesis Methods, 1, 272-283. doi: 10.1002/jrsm.23

Andrei, F., Mancini, G., Trombini, E., Baldaro, B., \& Russo, P. M. (2014). Testing the incremental validity of trait emotional intelligence: Evidence from an Italian sample of adolescents. Personality and Individual Differences, 64, 24-29. doi: j.paid.2014.02.007

**Andrei, F., \& Petrides, K. V. (2013). Trait emotional intelligence and somatic complaints with reference to positive and negative mood. Psihologija, 46, 5-15. doi:

\subsection{8/PSI1301005A}

Andrei, F., Smith, M. M., Surcinelli, P., Baldaro, B., \& Saklofske, D. H. (accepted). The trait emotional intelligence questionnaire: Internal structure, criterion and incremental 
validity in an Italian sample. Measurement and Evaluation in Counseling and Development.

Arora, S., Russ, S., Petrides, K. V., Sirimanna, P., Aggarwal, R., Darzi, A., \& Sevdalis, N. (2011). Emotional intelligence and stress in medical students performing surgical tasks. Academic Medicine, 86, 1311-1317. doi: 10.1097/ACM.0b013e31822bd7aa

Austin, E. J. (2010). Measurement of ability emotional intelligence: results for two new tests. British Journal of Psychology, 101, 563-578. doi: 10.1348/000712609X474370

Austin, E. J., Farrelly, D., Black, C., \& Moore, H. (2007). Emotional intelligence, Machiavellianism and emotional manipulation: Does EI have a dark side? Personality and Individual Differences, 43, 179-189. doi: 10.1016/j.paid.2006.11.019

Bar-On, R. (1997). Bar-On Emotional Quotient Inventory (EQ-i): A test of emotional intelligence. Toronto, Canada: Multi-Health Systems.

Brody, N. (2004). What cognitive intelligence is and what emotional intelligence is not. Psychological Inquiry, 15, 234-238.

Carroll, J. B. (1993). Human cognitive abilities: A survey of factor-analytic studies. New York: Cambridge University Press.

Caspi, A., Roberts, B. W., \& Shiner, R. L. (2005). Personality development: Stability and change. Annual Review of Psychology, 56, 453-484. doi:

10.1146/annurev.psych.55.090902.141913

**Chamorro-Premuzic, T., Bennett, E., \& Furnham, A. (2007). The happy personality: Mediational role of trait emotional intelligence. Personality and Individual Differences, 42, 1633-1639. doi: 10.1016/j.paid.2006.10.029

Cohen, J. (1988). Statistical power analysis for the behavioural sciences (2nd ed.). Hillsdale, NJ: Erlbaum. 
Collins, E., Freeman, J., \& Chamorro-Premuzic, T. (2012). Personality traits associated with problematic and non-problematic massively multiplayer online role playing game use. Personality and Individual Differences, 52, 133-138. doi: 10.1016/j.paid.2011.09.015

Conte, J. M. (2005). A review and critique of emotional intelligence measures. Journal of Organizational Behavior, 26, 433-440. doi: 10.1002/job.319

Cooper, A., \& Petrides, K. V. (2010). A psychometric analysis of the Trait Emotional Intelligence Questionnaire-Short Form using item response theory. Journal of Personality Assessment, 92, 449-457. doi: 10.1080/00223891.2010.497426

Costa, P. T., J., \& McCrae, R. R. (1992). Revised NEO personality inventory (NEO-PI-R) and NEO five-factor inventory (NEO-FFI): professional manual. Odessa: Psychological Assessment Resources.

Costa, P. T., \& McCrae, R. R. (1995). Domains and facets: Hierarchical personality assessment using the revised NEO personality inventory. Journal of Personality Assessment, 64, 21-50.

Credé, M., Harms, P., Niehorster, S., \& Gaye-Valentine, A. (2012). An evaluation of the consequences of using short measures of the Big Five personality traits. Journal of Personality and Social Psychology, 102, 874-888. doi: 10.1037/a0027403

Cronbach, L. J. (1949). Essentials of psychological testing. New York: Harper \& Row.

Di Fabio, A., \& Saklofske, D. H. (2014). Comparing ability and self-report trait emotional intelligence, fluid intelligence, and personality traits in career decision. Personality and Individual Differences, 64, 174-178. doi: 10.1016/j.paid.2014.02.024

Egger, M., Smith, G. D., Schneider, M., \& Minder, C. (1997). Bias in meta-analysis detected by a simple, graphical test. $B m j, 315,629-634$. 
Eysenck, H. J. (1994). The Big Five or Giant Three: criteria for a paradigm. In C. F. Halverson, G. A. Kohnstamm, \& R. P. Martin (Eds.), The developing structure of temperament and personality from infancy to adulthood. Hillsdale NJ: Erlbaum.

Eysenck, H. J., \& Eysenck, S. B. G. (1975). Manual of the Eysenck Personality Questionnaire. Journal of Personality Assessment (Vol. 43, pp. 43-55). Hodder and Stoughton. doi: 10.1177/014662168000400106

Faul, F., Erdfelder, E., Buchner, A., \& Lang, A. G. (2009). Statistical power analyses using G* Power 3.1: Tests for correlation and regression analyses. Behavior Research Methods, 41, 1149-1160. doi: 10.3758/BRM.41.4.1149

Ferguson, F. J., \& Austin, E. J. (2010). Associations of trait and ability emotional intelligence with performance on Theory of Mind tasks in an adult sample. Personality and Individual Differences, 49, 414-418. doi: 10.1016/j.paid.2010.04.009

Ferguson, C. J., \& Heene, M. (2012). A vast graveyard of undead theories: publication bias and psychological science's aversion to the null. Perspectives on Psychological Science, 7, 555-561. doi: 10.1177/1745691612459059

Fiori, M. (2009). A new look at emotional intelligence: A dual-process framework. Personality and Social Psychology Review, 13, 21-44. doi: $10.1177 / 1088868308326909$

Fisher, Z. \& Tipton, E. (2014). robumeta: Robust variance meta-regression. R package version 1.3. http://CRAN.R-project.org/package=robumeta.

**Freudenthaler, H. H., Neubauer, A. C., Gabler, P., Scherl, W. G., \& Rindermann, H. (2008). Testing and validating the trait emotional intelligence questionnaire (TEIQue) in a German-speaking sample. Personality and Individual Differences, 45, 673-678. doi:10.1016/j.paid.2008.07.014 
**Furnham, A., \& Christoforou, I. (2007). Personality traits, emotional intelligence, and multiple happiness. North American Journal of Psychology, 9, 439-462.

**Furnham, A., \& Petrides, K. V. (2003). Trait emotional intelligence and happiness. Social Behavior and Personality, 31, 815-824. doi: 10.2224/sbp.2003.31.8.815

**Gardner, K. J., \& Qualter, P. (2010). Concurrent and incremental validity of three trait emotional intelligence measures. Australian Journal of Psychology, 62, 5-13. doi: $10.1080 / 00049530903312857$

Harms, P. D., \& Credé, M. (2010). Remaining issues in emotional intelligence research: Construct overlap, method artifacts, and lack of incremental validity. Industrial and Organizational Psychology, 3, 154-158.

Hedges, L. V., Tipton, E., \& Johnson, M. C. (2010). Robust variance estimation in metaregression with dependent effect size estimates. Research Synthesis Methods, 1, 39-65. doi: $10.1002 / \mathrm{jrsm} .17$

Higgins, J., Thompson, S. G., Deeks, J. J., \& Altman, D. G. (2003). Measuring inconsistency in meta-analyses. BMJ, 327, 557-560. doi: 10.1136/bmj.327.7414.557

Hunsley, J., \& Meyer, G. J. (2003). The incremental validity of psychological testing and assessment: conceptual, methodological, and statistical issues. Psychological Assessment, 15, 446-455. doi: 10.1037/1040-3590.15.4.446

**Jolić-Marjanović, Z., \& Altaras-Dimitrijević, A. (2014). Reliability, construct and criterion-related validity of the Serbian adaptation of the Trait Emotional Intelligence Questionnaire (TEIQue). Psihologija, 47, 249-262. doi: 10.2298/PSI1402249J

Joseph, D. L., \& Newman, D. A. (2010). Emotional intelligence: An integrative metaanalysis and cascading model. Journal of Applied Psychology, 95, 54-78. 
**Laborde, S., Lautenbach, F., Allen, M. S., Herbert, C., \& Achtzehn, S. (2014). The role of trait emotional intelligence in emotion regulation and performance under pressure. Personality and Individual Differences, 57, 43-47. doi: 10.1016/j.paid.2013.09.013

*Laborde, S., You, M., Dosseville, F., \& Salinas, A. (2012). Culture, individual differences and situation: Influence on coping in French and Chinese table tennis players. European Journal of Sport Science, 12, 255-261. doi: $10.1080 / 17461391.2011 .566367$

MacCann, C., Matthews, G., Zeidner, M., \& Roberts, R. D. (2003). Psychological assessment of emotional intelligence: A review of self-report and performance-based testing. International Journal of Organizational Analysis, 11, 247-274. doi: 10.1108/eb028975

Martins, A., Ramalho, N., \& Morin, E. (2010). A comprehensive meta-analysis of the relationship between emotional intelligence and health. Personality and Individual Differences, 49, 554-564. doi: 10.1016/j.paid.2010.05.029

Martskvishvili, K., Arutinov, L., \& Mestvirishvili, M. (2013). A psychometric investigation of the Georgian version of the Trait Emotional Intelligence Questionnaire. European Journal of Psychological Assessment, 29, 1-5. doi: 10.1027/1015-5759/a000135

Matthews, G., Zeidner, M., \& Roberts, R. D. (2004). Emotional intelligence: Science and myth. Cambridge, MA: MIT Press.

Mavroveli, S., \& Sanchez-Ruiz, M. J. (2011). Trait emotional intelligence influences on academic achievement and school behaviour. British Journal of Educational Psychology, 81, 112-134. doi: dx.doi.org/10.1348/2044-8279.002009

**Mikolajczak, M., Luminet, O., Leroy, C., \& Roy, E. (2007). Psychometric properties of the Trait Emotional Intelligence Questionnaire: factor structure, reliability, construct, and 
incremental validity in a French-speaking population. Journal of Personality Assessment, 88, 338-353. doi: 10.1080/00223890701333431

**Mikolajczak, M., Luminet, O., \& Menil, C. (2006). Predicting resistance to stress: incremental validity of trait emotional intelligence over alexithymia and optimism. Psicothema, 18 Suppl, 79-88.

**Mikolajczak, M., Menil, C., \& Luminet, O. (2007). Exploring the protective effect of trait emotional intelligence regarding occupational stress: Exploration of emotional labour processes. Journal of Research in Personality, 41, 1107-1117. doi: 10.1016/j.jrp.2007.01.003

**Mikolajczak, M., Petrides, K. V., Coumans, N., \& Luminet, O. (2009). The moderating effect of trait emotional intelligence on mood deterioration following laboratoryinduced stress. International Journal of Clinical and Health Psychology, 9, 455-477.

**Mikolajczak, M., Roy, E., Luminet, O., Fillée, C., \& de Timary, P. (2007). The moderating impact of emotional intelligence on free cortisol responses to stress. Psychoneuroendocrinology, 32, 1000-1012. doi: 10.1016/j.psyneuen.2007.07.009

*Mikolajczak, M., Roy, E., Verstrynge, V., \& Luminet, O. (2009). An exploration of the moderating effect of trait emotional intelligence on memory and attention in neutral and stressful conditions. British Journal of Psychology, 100, 699-715. doi: $10.1348 / 000712608 \times 395522$

Neubauer, A. C., \& Freudenthaler, H. H. (2005). Models of emotional intelligence. In R. Schultz \& R. D. Roberts (Eds.), Emotional intelligence: An international, handbook (pp. 31-50). Cambridge, MA: Hogrefe.

Paunonen, S. V., \& Ashton, M. C. (2001). Big five factors and facets and the prediction of behavior. Journal of Personality and Social Psychology, 81, 524. doi: 10.1037/00223514.81 .3 .524 
Pérez-González, J. C., \& Sanchez-Ruiz, M. J. (2014). Trait emotional intelligence anchored within the Big Five, Big Two and Big One frameworks. Personality and Individual Differences, 65, 53-58. doi: 10.1016/j.paid.2014.01.021

Petrides, K. V. (2009). Psychometric properties of the Trait Emotional Intelligence Questionnaire. In C. Stough, D. H. Saklofske, and J. D. Parker (Eds), Advances in the Assessment of Emotional Intelligence. New York: Springer. doi: 10.1007/978-0-38788370-0_5

Petrides, K. V. (2011). Ability and trait emotional intelligence. In Chamorro-Premuzic, T., von Stumm, S., \& Furnham, A. (Eds.), The Wiley-Blackwell Handbook of Individual Differences (pp. 656-578). Blackwell Publishing Ltd.

Petrides, K. V., \& Furnham, A. (2000). On the dimensional structure of emotional intelligence. Personality and Individual Differences, 29, 313-320. doi: 10.1016/S0191-8869(99)00195-6

Petrides, K. V., \& Furnham, A. (2001). Trait emotional intelligence: Psychometric investigation with reference to established trait taxonomies. European Journal of Personality, 15, 425-448. doi: 10.1002/per.416

Petrides, K. V., \& Furnham, A. (2003). Trait emotional intelligence: Behavioural validation in two studies of emotion recognition and reactivity to mood induction. European Journal of Personality, 17, 39-57. doi: 10.1002/per.466

Petrides, K. V., \& Furnham, A. (2006). The role of trait emotional intelligence in a genderspecific model of organizational variables. Journal of Applied Social Psychology, 36(2), 552-569. doi:http://dx.doi.org/10.1111/j.0021-9029.2006.00019.x

**Petrides, K. V., Pérez-González, J. C., \& Furnham, A. (2007). On the criterion and incremental validity of trait emotional intelligence. Cognition \& Emotion, 21, 26-55. doi: 10.1080/02699930601038912 
**Petrides, K. V., Pita, R., \& Kokkinaki, F. (2007). The location of trait emotional intelligence in personality factor space. British Journal of Psychology, 98, 273-289. doi: 10.1348/000712606X120618

Petrides, K. V., Vernon, P. A., Schermer, J. A., Ligthart, L., Boomsma, D. I., \& Veselka, L. (2010). Relationships between trait emotional intelligence and the Big Five in the Netherlands. Personality and Individual Differences, 48, 906-910. doi: 10.1016/j.paid.2010.02.019

Petrides, K. V., Vernon, P. A., Schermer, J. A., \& Veselka, L. (2011). Trait emotional intelligence and the dark triad traits of personality. Twin Research and Human Genetics, 14, 35-41. doi: 10.1375/twin.14.1.35

Podsakoff, P. M., MacKenzie, S. B., Lee, J. Y., \& Podsakoff, N. P. (2003). Common method biases in behavioral research: a critical review of the literature and recommended remedies. Journal of Applied Psychology, 88, 879-903. doi: 10.1037/00219010.88.5.879

R Core Team (2012). R: A language and environment for statistical computing. R Foundation for Statistical Computing, Vienna, Austria. ISBN 3-900051-07-0, http://www.Rproject.org/.

Rosenthal, R. (1979). The file drawer problem and tolerance for null results. Psychological Bulletin, 86, 638-641. doi:10.1037/0033-2909.86.3.638

Russo, P. M., Mancini, G., Trombini, E., Baldaro, B., Mavroveli, S., \& Petrides, K. V. (2012). Trait emotional intelligence and the big five: a study on Italian children and preadolescents. Journal of Psychoeducational Assessment, 30, 274-283. doi: $10.1177 / 0734282911426412$

Salovey, P., \& Mayer, J. D. (1990). Emotional intelligence. Imagination, Cognition and Personality, 9, 185-211. 
**Sanchez-Ruiz, M. J., Mavroveli, S., \& Poullis, J. (2013). Trait emotional intelligence and its link to university performance: an examination. Personality and Individual Differences, 54, 658-662. doi: 10.1016/j.paid.2012.11.013

Saucier, G. (1994). Mini-markers: A brief version of Goldberg's unipolar Big-Five markers. Journal of Personality Assessment, 63, 506-516. doi: 10.1207/s15327752jpa6303_8

Schlegel, K., Grandjean, D., \& Scherer, K. R. (2013). Constructs of social and emotional effectiveness: Different labels, same content? Journal of Research in Personality, 47, 249-253. doi: 10.1016/j.jrp.2013.02.005

Schulte, M. J., Ree, M. J., \& Carretta, T. R. (2004). Emotional intelligence: Not much more than $g$ and personality. Personality and Individual Differences, 37, 1059-1068. doi: 10.1016/j.paid.2003.11.014

Siegling, A. B., Petrides, K. V., \& Martskvishvili, K. (2015). An examination of a new psychometric method for optimizing multi-faceted assessment instruments in the context of trait emotional intelligence. European Journal of Personality, 29, 42-54. doi: 10.1002/per.1976.

*Siegling, A. B., Nielsen, C., \& Petrides, K. V. (2014). Trait emotional intelligence and leadership in a European multinational company. Personality and Individual Differences, 65, 65-68. doi: dx.doi.org/10.1016/j.paid.2014.01.049

Siegling, A. B., Petrides, K. V., \& Saklofske, D. H (2015). Measures of Ability and Trait Emotional Intelligence. In G. J. Boyle \& Saklofske D. H. \& G. Matthews (Eds.): Measures of Personality and Social Psychological Constructs (pp. 381-411). Academic Pres.

**Siegling, A. B., Vesely, A. K., Petrides, K. V., \& Saklofske, D. H. (2015). Incremental validity of the Trait Emotional Intelligence Questionnaire-Short Form (TEIQue-SF). Journal of Personality Assessment. (ahead-of-print), 1-11. 
Siegling, A. B., Vesely, A. K., Saklofske, D. H., Frederickson, N. L., \& Petrides, K. V. (accepted). Incremental validity of the Trait Emotional Intelligence QuestionnaireAdolescent Short Form (TEIQue-ASF). European Journal of Personality Assessment.

Siegling, A. B., Vesely, A. K., \& Saklofske, D. H. (2013). Advancing the trait EI content domain: Further evidence for the distinctiveness of interpersonal facets. Personality and Individual Differences, 54, 81-86. doi: 10.1016/j.paid.2012.08.010

Sinclair, H., \& Feigenbaum, J. (2012). Trait emotional intelligence and borderline personality disorder. Personality and Individual Differences, 52, 674-679. doi: 10.1016/j.paid.2011.12.022

**Singh, M., \& Woods, S. A. (2008). Predicting general well-being from emotional intelligence and three broad personality traits. Journal of Applied Social Psychology, 38, 635-646. doi: 10.1111/j.1559-1816.2007.00320.x

Smith, L., Heaven, P. C. L., \& Ciarrochi, J. (2008). Trait emotional intelligence, conflict communication patterns, and relationship satisfaction. Personality and Individual Differences, 44, 1314-1325. doi: 10.1016/j.paid.2007.11.024

Sterne, J. A. C., \& Egger, M. (2001). Funnel plots for detecting bias in meta-analysis: Guidelines on choice of axis. Journal of Clinical Epidemiology, 54, 1046-1055. doi:10.1016/S0895-4356(01)00377-8

**Swami, V., Begum, S., \& Petrides, K. V. (2010). Associations between trait emotional intelligence, actual-ideal weight discrepancy, and positive body image. Personality and Individual Differences, 49, 485-489. doi: 10.1016/j.paid.2010.05.009

*Uva, M. C. D. S., de Timary, P., Cortesi, M., Mikolajczak, M., du Roy de Blicquy, P., \& Luminet, O. (2010). Moderating effect of emotional intelligence on the role of negative affect in the motivation to drink in alcohol-dependent subjects undergoing 
protracted withdrawal. Personality and Individual Differences, 48, 16-21. doi: 10.1016/j.paid.2009.08.004

Van der Linden, D., Tsaousis, I., \& Petrides, K. V. (2012). Overlap between General Factors of Personality in the Big Five, Giant Three, and trait emotional intelligence. Personality and Individual Differences, 53, 175-179. doi: 10.1016/j.paid.2012.03.001

*van Leeuwen, B. M., Borst, J. M., Putter, H., Jansen, J. C., van der Mey, A. G., \& Kaptein, A. A. (2014). Emotional intelligence in association with quality of life in patients recently diagnosed with vestibular schwannoma. Otology \& Neutrology, 35, 16501657. doi: 10.1097/MAO.0000000000000423

Vernon, P. A., Villani, V. C., Schermer, J. A., \& Petrides K. V. (2008). Phenotypic and genetic associations between the big five and trait emotional intelligence. Twin Research and Human Genetics, 11, 524-530. doi: 10.1375/twin.11.5.524

Viechtbauer, W. (2010). Conducting meta-analyses in R with the metafor package. Journal of Statistical Software, 36, 1-48. http://www.jstatsoft.org/v36/i03/

Watson, D., Clark, L. A., \& Tellegen, A. (1988). Development and validation of brief measures of positive and negative affect: the PANAS scales. Journal of Personality and Social Psychology, 54, 1063-1070. doi: 10.1037/0022-3514.54.6.1063

*Weaving, J., Orgeta, V., Orrell, M., \& Petrides, K. V. (2014). Predicting anxiety in carers of people with dementia: the role of trait emotional intelligence. International Psychogeriatrics, 26, 1201-1209. doi: 10.1017/S1041610214000404

Ybarra, O., Kross, E., \& Sanchez-Burks, J. (2014). The "big idea" that is yet to be: Toward a more motivated, contextual, and dynamic model of emotional intelligence. The Academy of Management Perspectives, 28, 93-107. doi: 10.5465/amp.2012.0106 
Zeidner, M., Matthews, G., \& Roberts, R. D. (2012). Emotional intelligence, health, and well-being nexus: What we have learned and what we have missed? Applied Psychology, Health and Well-Being, 4, 1-30. doi: 10.1111/j.1758-0854.2011.01062.x 
Table 1

The Sampling Domain of Trait EI in Adults (Petrides, 2009)

Factors Facets High scorers perceive themselves as

Well-Being

Trait optimism ...confident and likely to 'look on the bright side' of life...

Trait happiness $\quad$...cheerful and satisfied with their lives...

Self-esteem $\quad$...successful and self-confident...

Sociability

Emotion management ...capable of influencing other people's feelings... (others)

Assertiveness $\quad$...forthright, frank and willing to stand up for their rights...

Social awareness $\quad$...accomplished networkers with excellent social skills...

Emotionality

Trait empathy $\quad$...capable of taking someone else's perspective...

Emotion perception ...clear about their own and other people's feelings...

(self and others)

Emotion expression ...capable of communicating their feelings to others...

Relationships $\quad$...capable of having fulfilling personal relationships...

Self-Control

Emotion regulation ...capable of controlling their emotions...

Impulsiveness (low) $\quad$...reflective and less likely to give in to their urges...

Stress management $\quad$...capable of withstanding pressure and regulating stress...

Auxiliary facets

Self-motivation

...driven and unlikely to give up in the face of adversity...

Adaptability

...flexible and willing to adapt to new conditions... 
Table 2

Summary of Studies Examining the Incremental Validity of Trait EI Using the Full Form of the Trait Emotional Intelligence Questionnaire

(TEIQue; $n$ of analyses $=82$ )

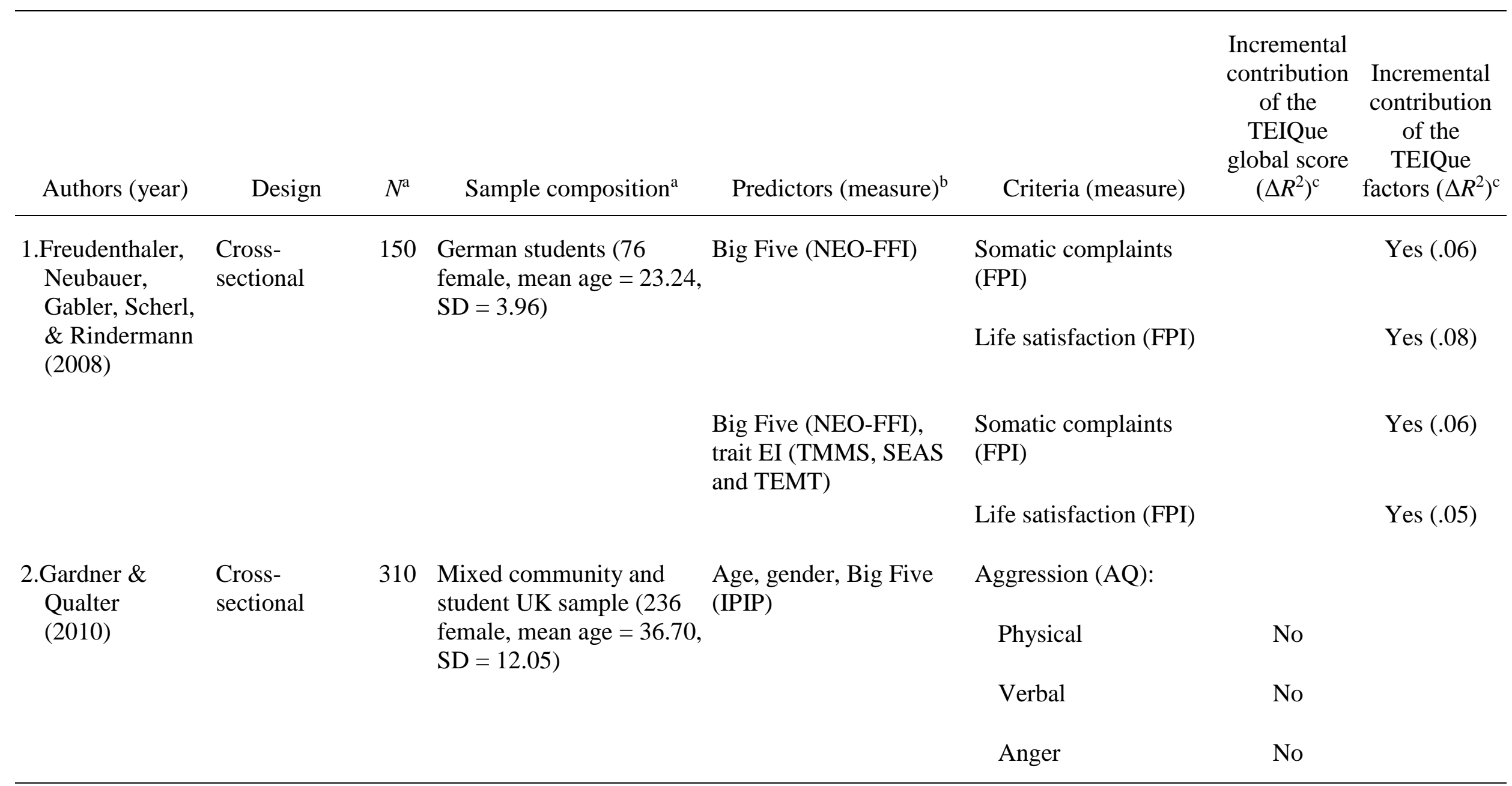




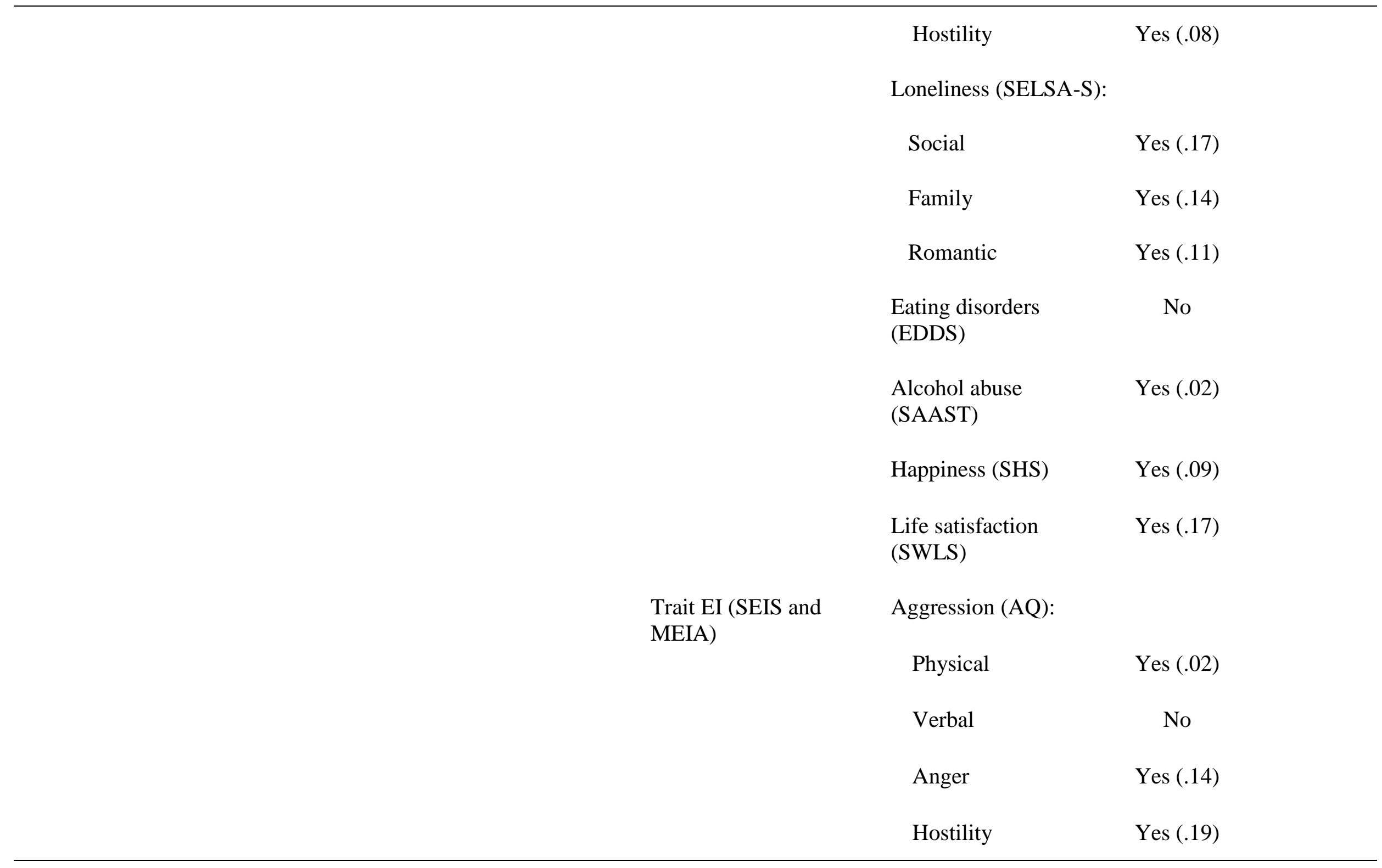


Loneliness (SELSA-S):

\begin{tabular}{|c|c|}
\hline Social & Yes (.08) \\
\hline Family & Yes (.06) \\
\hline Romantic & Yes (.04) \\
\hline $\begin{array}{l}\text { Eating disorders } \\
\text { (EDDS) }\end{array}$ & Yes (.10) \\
\hline $\begin{array}{l}\text { Alcohol abuse } \\
\text { (SAAST) }\end{array}$ & Yes (.07) \\
\hline Happiness (SHS) & Yes (.22) \\
\hline $\begin{array}{l}\text { Life satisfaction } \\
\text { (SWLS) }\end{array}$ & Yes (.19) \\
\hline Well-being (RSPWB-S) & Yes (.07) \\
\hline Well-being (RSPWB-S) & Yes $(.25)$ \\
\hline $\begin{array}{l}\text { Biological marker of } \\
\text { emotion regulation } \\
\text { (cortisol secretion) }\end{array}$ & Yes (.28) \\
\hline
\end{tabular}

3.Jolić-Marjanović Cross-

\& Altaras- sectional

Dimitrijević

(2014)
254 Serbian adults (117 female, mean age $=40.21$, $\mathrm{SD}=8.17$ )

\section{Big Five (NEO-FFI)}

Ability EI (MSCEIT), Well-being (RSPWB-S) Yes (.25) empathy (EQ-Short)
4.Laborde,
Lautenbach,
Experimental
Allen, Herbert,
28 German speaking tennis players (13 female, mean age $=23.88, \mathrm{SD}=$ n. r.)

\& Achtzehn 
(2014)

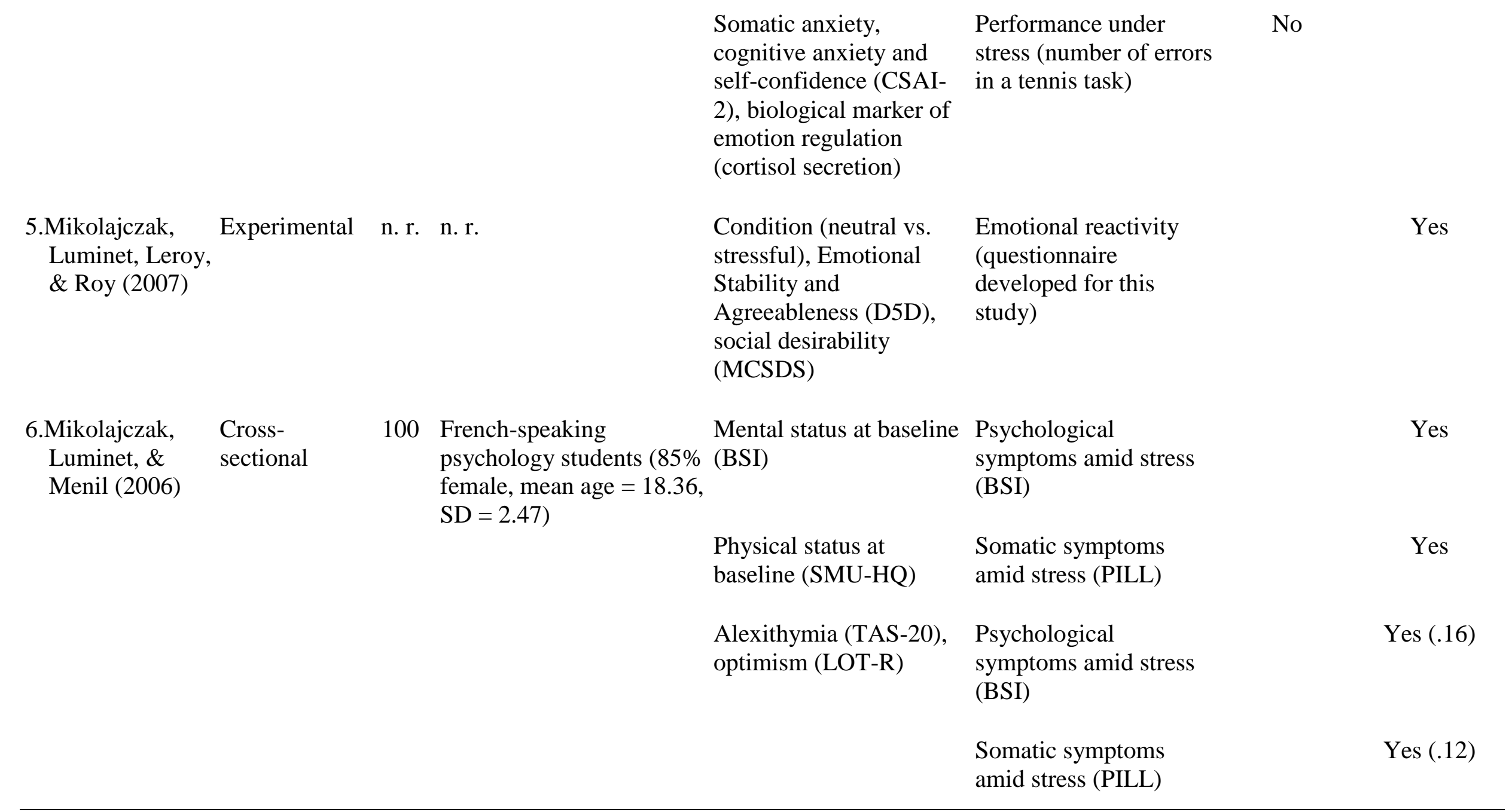




\begin{tabular}{|c|c|c|c|c|c|c|}
\hline \multirow[t]{3}{*}{$\begin{array}{l}\text { 7.Mikolajczak, } \\
\text { Petrides, } \\
\text { Coumans, \& } \\
\text { Luminet }(2009)^{\mathrm{d}}\end{array}$} & Experimental & 118 & $\begin{array}{l}\text { French speaking students } \\
(51 \text { female, mean age }= \\
18.70, \mathrm{SD}=1.04)\end{array}$ & $\begin{array}{l}\text { Condition (neutral vs. } \\
\text { stressful), negative affect } \\
\text { at baseline (PANAS), } \\
\text { Emotional Stability, } \\
\text { Agreeableness, Openness } \\
\text { (D5D), alexithymia } \\
\text { (TAS-20), social } \\
\text { desirability (MCSDS) }\end{array}$ & $\begin{array}{l}\text { Negative affect at } \\
\text { follow-up (PANAS) }\end{array}$ & Yes \\
\hline & & & & $\begin{array}{l}\text { Social desirability } \\
\text { (MCSDS) }\end{array}$ & $\begin{array}{l}\text { Negative affect at } \\
\text { follow-up (PANAS) }\end{array}$ & Yes \\
\hline & & & & $\begin{array}{l}\text { Social desirability } \\
\text { (MCSDS) }\end{array}$ & $\begin{array}{l}\text { Positive affect at } \\
\text { follow-up (PANAS) }\end{array}$ & Yes \\
\hline
\end{tabular}




\begin{tabular}{|c|c|c|c|c|c|c|}
\hline Study 2 & As above & 56 & $\begin{array}{l}\text { French-speaking male } \\
\text { students (mean age }= \\
20.18, \mathrm{SD}=2.02)\end{array}$ & $\begin{array}{l}\text { Condition (neutral vs. } \\
\text { stressful), negative affect } \\
\text { at baseline (PANAS), } \\
\text { resilience (RSA) }\end{array}$ & $\begin{array}{l}\text { Negative affect at } \\
\text { follow-up (PANAS) }\end{array}$ & Yes \\
\hline \multirow[t]{2}{*}{$\begin{array}{l}\text { 8.Mikolajczak, } \\
\text { Roy, Luminet, } \\
\text { Fillée, \& de } \\
\text { Timary (2007) }\end{array}$} & Experimental & 56 & As above & $\begin{array}{l}\text { Condition (neutral vs. } \\
\text { stressful), interaction } \\
\text { terms of condition with: } \\
\text { Emotional Stability, } \\
\text { Agreeableness, Openness } \\
\text { (D5D) and alexithymia } \\
\text { (TAS-20) }\end{array}$ & $\begin{array}{l}\text { Biological responses to } \\
\text { stress (cortisol } \\
\text { secretion) }\end{array}$ & Yes (.04) \\
\hline & & & & $\begin{array}{l}\text { Condition (neutral vs. } \\
\text { stressful), Emotional } \\
\text { Stability, Agreeableness, } \\
\text { Openness (D5D), social } \\
\text { desirability (MCSDS), } \\
\text { condition } \times \text { alexithymia } \\
\text { (TAS-20) }\end{array}$ & $\begin{array}{l}\text { Psychological responses } \\
\text { to stress (PANAS) }\end{array}$ & Yes (.03) \\
\hline $\begin{array}{l}\text { 9.Mikolajczak, } \\
\text { Roy, } \\
\text { Verstrynge, \& } \\
\text { Luminet } \\
(2009)^{\mathrm{e}}\end{array}$ & Experimental & 62 & $\begin{array}{l}\text { Belgian psychology } \\
\text { students }(47 \text { female, mean } \\
\text { age }=18.69, \mathrm{SD}=1.05)\end{array}$ & $\begin{array}{l}\text { Big Five (D5D), social } \\
\text { desirability (MCSDS), } \\
\text { depression (BDI), } \\
\text { anxiety (STAI-T) }\end{array}$ & $\begin{array}{l}\text { Attention deployment } \\
\text { (visual dot probe task) }\end{array}$ & \\
\hline $\begin{array}{l}\text { 10.Petrides, } \\
\text { Pérez- } \\
\text { González, \& }\end{array}$ & $\begin{array}{l}\text { Cross- } \\
\text { sectional }\end{array}$ & 200 & $\begin{array}{l}\text { UK students }(125 \text { female, } \\
\text { mean age }=22.86, \mathrm{SD}= \\
6.17)\end{array}$ & Big Five (NEO PI-R) & $\begin{array}{l}\text { Coping (CSQ): } \\
\text { Rational }\end{array}$ & Yes \\
\hline
\end{tabular}




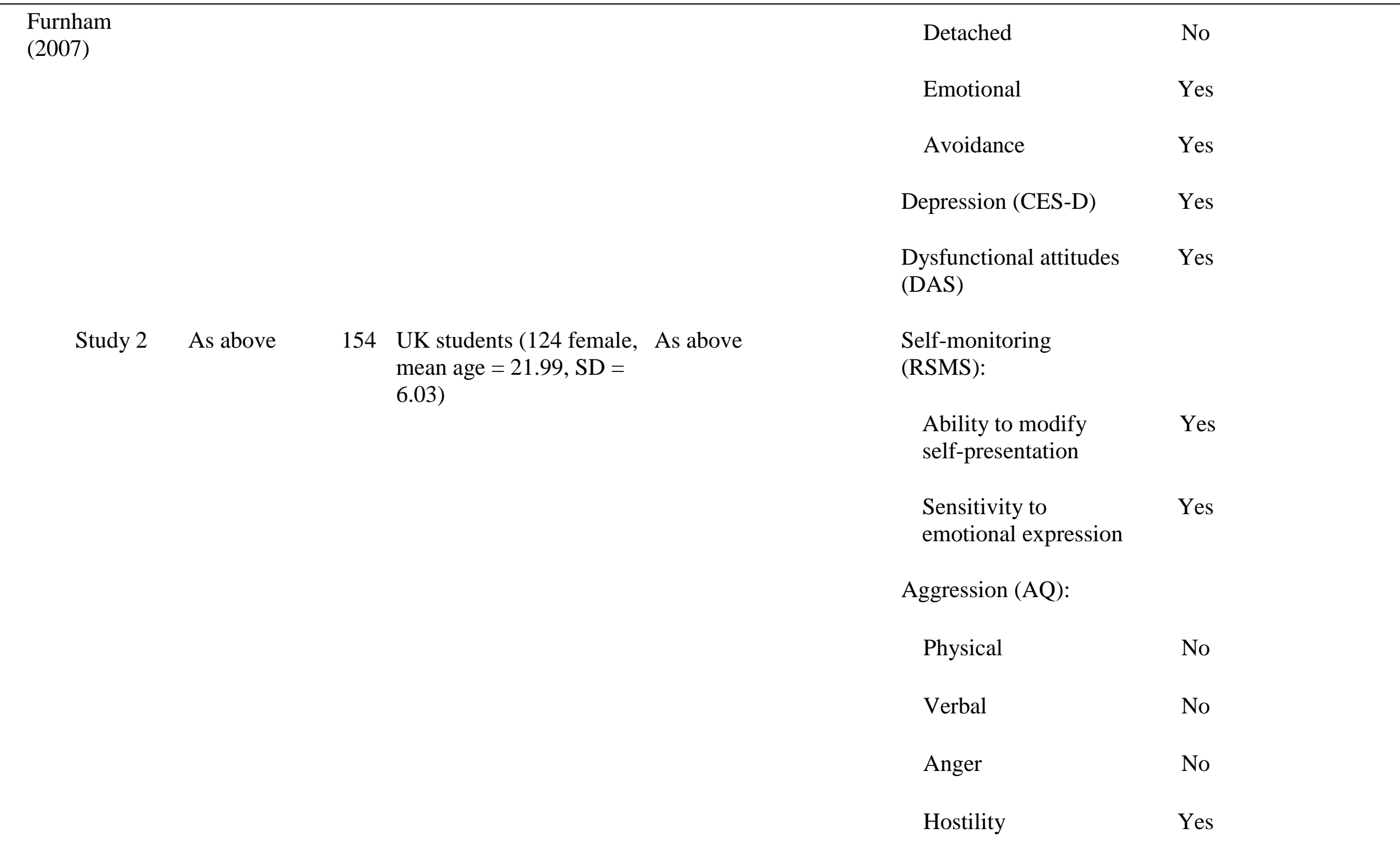




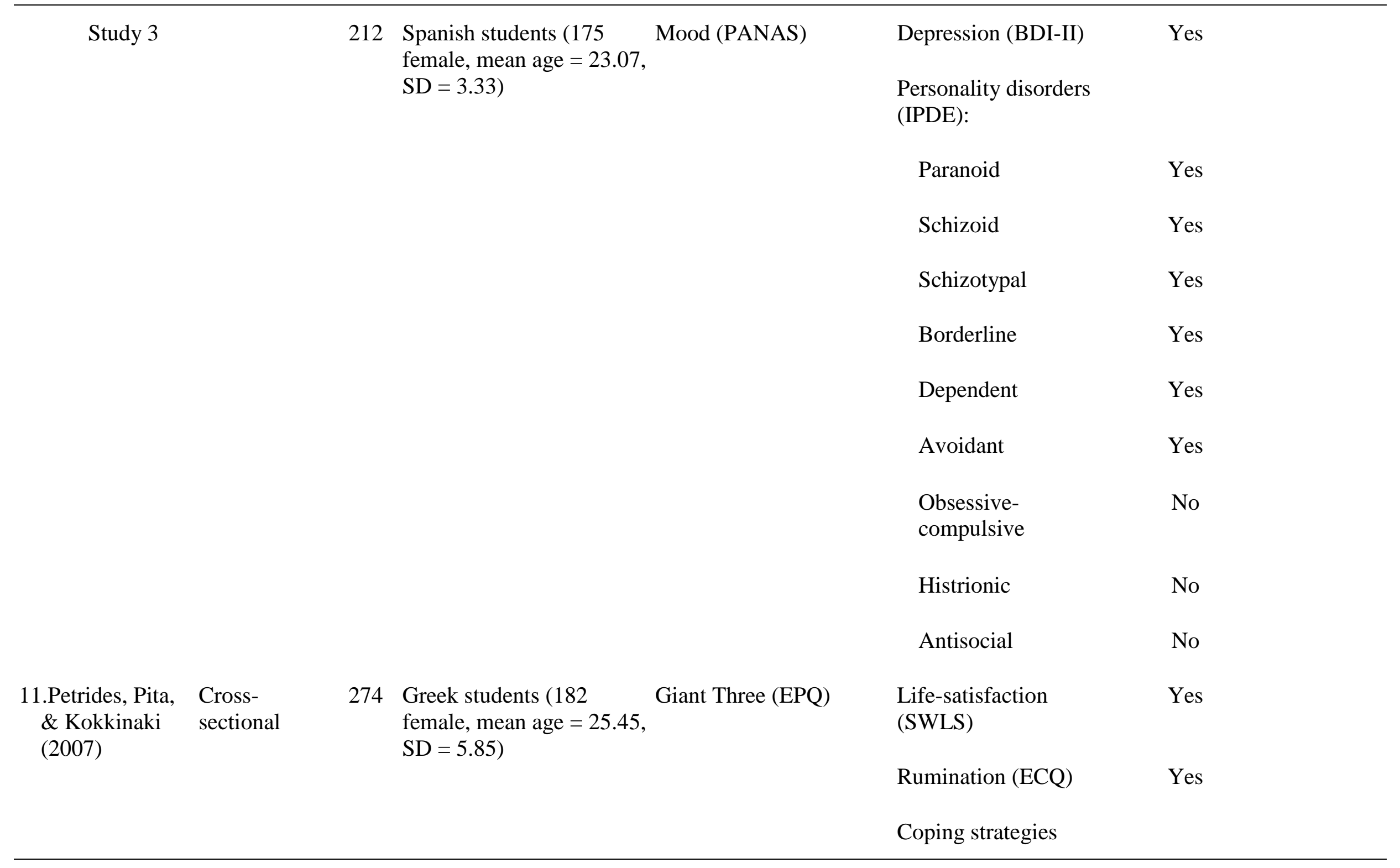


(CSQ):

\begin{tabular}{|c|c|c|c|}
\hline & Rational & Yes & \\
\hline & Detached & No & \\
\hline & Emotional & Yes & \\
\hline & Avoidant & No & \\
\hline Big Five (ТЕХАП) & $\begin{array}{l}\text { Life-satisfaction } \\
\text { (SWLS) }\end{array}$ & Yes & \\
\hline & Rumination (ECQ) & Yes & \\
\hline & $\begin{array}{l}\text { Coping strategies } \\
\text { (CSQ): }\end{array}$ & & \\
\hline & Rational & Yes & \\
\hline & Detached & Yes & \\
\hline & Emotional & Yes & \\
\hline & Avoidant & No & \\
\hline $\begin{array}{l}\text { Body mass index as } \\
\mathrm{kg} / \mathrm{m}^{2} \text { (self-reported } \\
\text { height and weight), }\end{array}$ & $\begin{array}{l}\text { Actual-ideal weight } \\
\text { discrepancy (PFRS) }\end{array}$ & & Yes (.06) \\
\hline $\begin{array}{l}\text { impact of socio-cultural } \\
\text { influences on body image }\end{array}$ & Body appreciation & & Yes (.25) \\
\hline
\end{tabular}

12. Swami,

Begum, \&

Petrides (2010)
Cross-

sectional
108 British female students Body mass index as (mean age $=23.94, \mathrm{SD}=\mathrm{kg} / \mathrm{m}^{2}$ (self-reported 4.28) 
13.Uva et al. Longitudinal (2010)

14.van Leeuwen, Cross-

Borst, Putter, sectional Jansen, van der Mey, \& Kaptein (2014)
41 French inpatients $(n=41$; Negative affect $47.9 \%$ female, mean age $=($ PANAS $)$ $50.6, \mathrm{SD}=9.4$ )

178 Dutch patient with vestibular schwannoma diagnosis (83 female, mean age $=56.4$ )

\section{(SATAQ-3)}

\section{(BAS)}

Craving (OCD)

Yes

Balance disorder, cranial Quality of life nerve dysfunction, educational level

Note. $\mathrm{AQ}=$ Aggression Questionnaire; BAS = Body Appreciation Scale; BDI-II = Beck Depression Inventory-II; BSI = Brief Symptom Inventory; CES-D = Center for Epidemiologic Studies Depression Scale; CSAI-2 = Competitive State Anxiety-2; CSQ = Coping Style

Questionnaire; DAS = Dysfunctional Attitudes Scale; D5D = Description en Cinq Dimensions; ECQ = Emotion Control Questionnaire; EDDS = Eating Disorders Diagnostic Scale; EPQ = Eysenck Personality Questionnaire; EQ-Short = Empathy Quotient Short; FPI = Freiburger Persönlichkeitsinventar; IPDE = International Personality Disorder Examination; IPIP = International Personality Item Pool; LOT-R = Life

Orientation Test-Revised; MCSDS = Marlowe-Crowne Social Desirability Scale; MEIA = Multidimensional Emotional Intelligence Assessment; MSCEIT = Mayer-Salovey-Caruso Emotional Intelligence Test; NEO-FFI = Neo-Five Factor Inventory; OCD = ObsessiveCompulsive Drinking Scale; PANAS = Positive and Negative Affect Schedule; PANQUOL = Penn Acoustic Neuroma Quality of Life ScaleDutch Version; PFRS = Photographic Figure Rating Scale; PILL = Physical Inventory of Limbic Languidness; RSA = Resilience Scale for Adult; RSMS = Revised Self-Monitoring Scale; RSPWB-S = Ryff's Scales of Psychological Well-Being Short; SAAST = Self-Administered 
Alcoholism Screening Test; SATAQ-3 = Socio-cultural Attitudes Toward Appearance Questionnaire-3; SEAS = Self-report Emotional Ability Scale; SEIS = Schutte Emotional Intelligence Scale; SELSA-S = Social Emotional Loneliness Scale for Adults-Short form; SHS = Subjective Happiness Scale; SMU-HQ = Southern Methodist University Health Questionnaire; STAI-T = State Trait Anxiety Inventory; SWLS = Satisfaction with Life Scale; TAS-20 = Toronto Alexithymia Scale; TEMT = Typical-Performance Emotional Management Test; TEXAП = Traits Personality Questionnaire; TMMS = Trait Meta-Mood Scale.

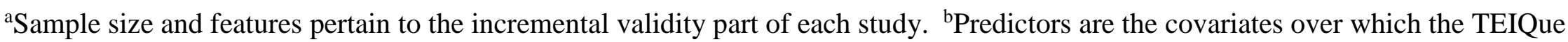
incrementally predicts the study criteria. ${ }^{c}$ Entries in this column are necessarily succinct and present only specific findings of interest. They are not intended as a summary of the original research articles, which interested readers are urged to consult. Incremental validity statistics were not provided in all studies. ${ }^{\mathrm{d}}$ Data from this study were supplemented by communication with the first author. This communication resulted in effect sizes that were not reported in the original study. ${ }^{\mathrm{e}}$ This study uses ANOVAs. 
Table 3

Summary of Studies Examining the Incremental Validity of Trait EI Using the Trait Emotional Intelligence Questionnaire-Short Form (TEIQueSF; $n$ of analyses $=32$ )

\begin{tabular}{|c|c|c|c|c|c|c|c|}
\hline Authors (year) & Design & $N^{\mathrm{a}}$ & Sample composition ${ }^{\mathrm{a}}$ & Predictors (measure) ${ }^{\mathrm{b}}$ & Criteria (measure) & $\begin{array}{l}\text { Incremental } \\
\text { contribution } \\
\text { for the } \\
\text { TEIQue } \\
\text { global score } \\
\left(\Delta R^{2}\right)^{\mathrm{c}}\end{array}$ & $\begin{array}{l}\text { Incremental } \\
\text { contribution } \\
\text { for the } \\
\text { TEIQue } \\
\text { factors } \\
\left(\Delta R^{2}\right)^{\mathrm{c}}\end{array}$ \\
\hline $\begin{array}{l}\text { 1.Andrei \& } \\
\text { Petrides } \\
\text { (2013) }\end{array}$ & $\begin{array}{l}\text { Cross- } \\
\text { sectional }\end{array}$ & 362 & $\begin{array}{l}\text { Community volunteers } \\
(140 \text { female, mean age }= \\
33.69, \mathrm{SD}=11.92)\end{array}$ & Mood (PANAS) & Somatic complaints (SCL) & Yes $(.04)$ & \\
\hline $\begin{array}{l}\text { 2.Chamorro- } \\
\text { Premuzic, } \\
\text { Bennett, \& } \\
\text { Furnham } \\
(2007)\end{array}$ & $\begin{array}{l}\text { Cross- } \\
\text { sectional }\end{array}$ & 112 & $\begin{array}{l}\text { Mixed student and } \\
\text { community British sample } \\
(61 \text { female, mean age }= \\
25.1, \mathrm{SD}=9.4)\end{array}$ & $\begin{array}{l}\text { Gender, age, and Big } \\
\text { Five (TIPI) }\end{array}$ & Happiness (OHI) & Yes $(.18)$ & \\
\hline \multirow[t]{3}{*}{$\begin{array}{l}\text { 3.Furnham \& } \\
\text { Christoforou } \\
\text { (2007) }\end{array}$} & $\begin{array}{l}\text { Cross- } \\
\text { sectional }\end{array}$ & 120 & $\begin{array}{l}\text { Greek community sample } \\
(76 \text { female, mean age }= \\
36.5, \mathrm{SD}=12.5)\end{array}$ & $\begin{array}{l}\text { Giant Three (EPQ), } \\
\text { multiple happiness } \\
\text { (MMHI) }\end{array}$ & Happiness (OHI) & Yes & \\
\hline & & & & $\begin{array}{l}\text { Giant Three (EPQ), } \\
\text { happiness }(\mathrm{OHI})\end{array}$ & $\begin{array}{l}\text { Interpersonal happiness } \\
\text { (MMHI) }\end{array}$ & Yes & \\
\hline & & & & & Sensation seeking (MMHI) & No & \\
\hline
\end{tabular}




\begin{tabular}{|c|c|c|c|c|c|c|c|}
\hline $\begin{array}{l}\text { 4.Furnham \& } \\
\text { Petrides } \\
\text { (2003) }\end{array}$ & $\begin{array}{l}\text { Cross- } \\
\text { sectional }\end{array}$ & 88 & $\begin{array}{l}\text { Undergraduate students } \\
(77 \text { female, mean age }= \\
19.79, \mathrm{SD}=.83)\end{array}$ & Big Five (NEO-FFI) & Happiness (OHI) & Yes & \\
\hline \multirow{7}{*}{$\begin{array}{l}\text { 5.Mikolajczak, } \\
\text { Menil, \& } \\
\text { Luminet } \\
\text { (2007) }\end{array}$} & $\begin{array}{l}\text { Cross- } \\
\text { sectional }\end{array}$ & 124 & $\begin{array}{l}\text { Nurses }(85 \% \text { female, mean } \\
\text { age }=39.4, \mathrm{SD}=9)\end{array}$ & Big Five (D5D) & $\begin{array}{l}\text { Emotional labour process } \\
\text { (D-Quel): }\end{array}$ & & \\
\hline & & & & & Surface acting & Yes $(.08)$ & \\
\hline & & & & & Deep acting & Yes $(.07)$ & \\
\hline & & & & & Positive consonance & Yes (.04) & \\
\hline & & & & & Negative consonance & No & \\
\hline & & 49 & & & Somatic complaints (PILL) & No & \\
\hline & & & & & Burnout (MBI) & Yes $(.08)$ & \\
\hline $\begin{array}{l}\text { 6.Sanchez- } \\
\text { Ruiz, } \\
\text { Mavroveli, \& } \\
\text { Poullis } \\
\text { (2013) }\end{array}$ & $\begin{array}{l}\text { Cross- } \\
\text { sectional }\end{array}$ & 323 & $\begin{array}{l}\text { Cypriot university } \\
\text { students }(113 \text { female, } \\
\text { mean age }=23, \mathrm{SD}= \\
1.65)\end{array}$ & $\begin{array}{l}\text { Big Five (TIPI), } \\
\text { cognitive ability (BRT), } \\
\text { university majors }\end{array}$ & $\begin{array}{l}\text { Academic performance } \\
\text { (GPA) }\end{array}$ & Yes $(.03)$ & \\
\hline $\begin{array}{l}\text { 7.Siegling, } \\
\text { Vesley, } \\
\text { Petrides, \& }\end{array}$ & $\begin{array}{l}\text { Cross- } \\
\text { sectional }\end{array}$ & 645 & $\begin{array}{l}\text { Canadian undergraduate } \\
\text { students }(71.5 \% \text { female, } \\
\text { mean age }=22.6, \mathrm{SD}=5.4)\end{array}$ & $\begin{array}{l}\text { Big Five (BFI), coping } \\
\text { strategies (CISS) }\end{array}$ & Perceived Stress (PSS) & Yes $(.01)$ & Yes (.02) \\
\hline Saklofske & & & & & Anxiety (OASIS) & Yes $(.01)$ & Yes (.01) \\
\hline
\end{tabular}


(2014)

Study 2 As above

9.Singh \&

Woods

(2008)

Cross-

sectional

$\begin{array}{ll} & \\ \text { 10.Weaving, Cross- } \\ \text { Orgeta, } & \text { sectional } \\ \text { Orrell, \& } & \\ \text { Petrides } & \\ \text { (2014) } & \end{array}$

44

As above $(72.3 \%$ female mean age $=22.6, \mathrm{SD}=5.4$ )

Amotivation

Depression (DASS)

Anxiety (DASS)

Stress (DASS)

Life satisfaction (SWLS)

Age, gender, cognitive Leadership (position held ability (in-house within the company) multinational company (25 female, mean age $=$ $37.09, \mathrm{SD}=7.73$ )

Wonderlic-type test),

job tenure

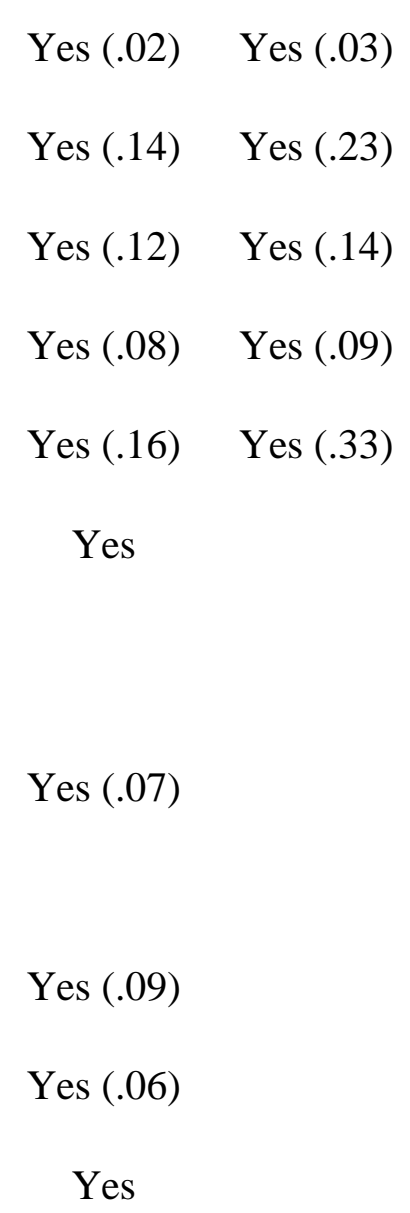

Yes

Neuroticism (BFI) Well-being (GWBQ):
Job satisfaction (OJSQ) Yes (.07) 
Note. BFI = Big Five Inventory; BFMM = Big Five Mini-Markers; Brief COPE = Brief Coping Orientations to Problems Experienced; BRT = Baddeley Reasoning Test; CISS = Coping Inventory for Stressful Situations; DASS = Depression, Anxiety, and Stress Scales; D5D = Description en Cinq Dimensions; D-Quel = Dutch Questionnaire of Emotional labour; EPQ = Eysenck Personality Questionnaire; EQ5D VAS = EQ-5D Visual Analogue Scale; GPA = Grade Point Average; GWBQ = General Well-Being Questionnaire; HADS = Hospital Anxiety and Depression Scale; MBI = Maslach Burnout Inventory; MMHI = Morris Multiple Happiness Inventory; NEO-FFI = Neo-Five Factor Inventory; OASIS = Overall Anxiety Severity Impairment Scale; OHI = Oxford Happiness Inventory; OJSQ = Overall Job Satisfaction Questionnaire; PANAS = Positive and Negative Affect Schedule; PILL = Physical Inventory of Limbic Languidness; PSS = Perceived Stress Scale; RSS = Relatives' Stress Scale; SCL = Somatic Complaint List; SWLS = Satisfaction With Life Scale; TIPI = Ten Item Personality Inventory.

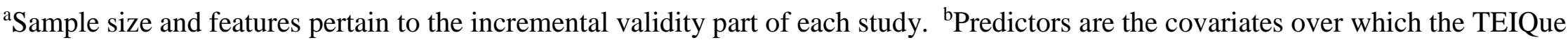
incrementally predicts the study criteria. ${ }^{\mathrm{c}}$ Entries in this column are necessarily succinct and present only specific findings of interest. They are not intended as a summary of the original research articles, which interested readers are urged to consult. Incremental validity statistics were not provided in all studies. ${ }^{\mathrm{d}}$ In this study, 40 participants completed the TEIQue and 56 completed the TEIQue-SF. 
Table 4

Results of Meta-Analysis

\begin{tabular}{llllll}
\hline \multicolumn{1}{c}{ Model } & & Estimate & SE & $95 \%$ CI & $I^{2}$ \\
\hline Overall & Intercept & $.06^{* *}$ & .0116 & $0.03-0.08$ & $39.3 \%$ \\
Moderator & & & & & \\
Length of personality questionnaire & Intercept (long-size) & $.01^{*}$ & .0036 & $0.00-0.02$ & $11.75 \%$ \\
& Slope (medium-size) & $.04^{*}$ & .0114 & $0.01-0.07$ & .0274 \\
& Slope (short-size) & $-0.01-0.12$ \\
\hline
\end{tabular}

$* p<.05, * * p<.01$ 


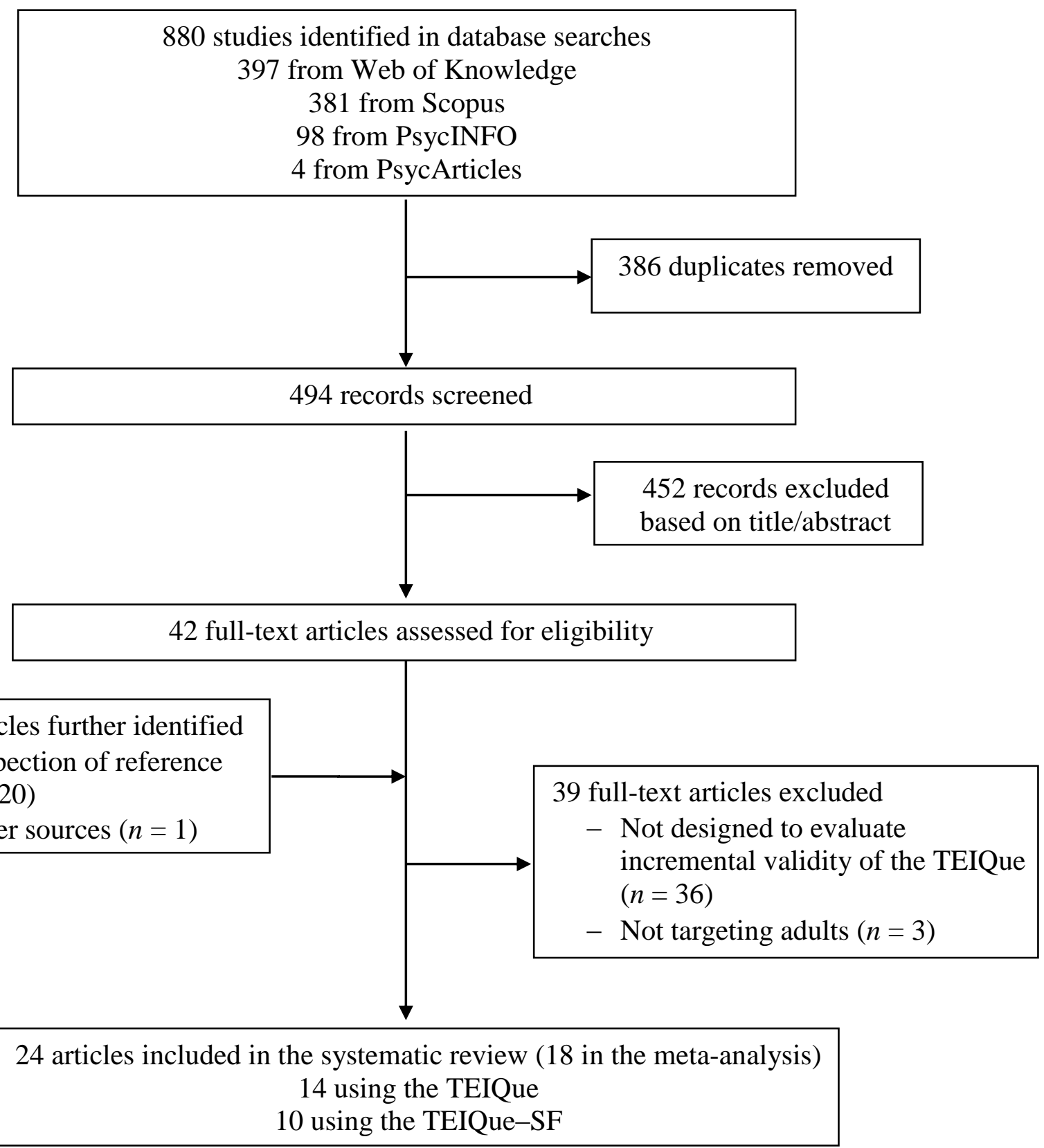

Figure 1. Flow diagram of review process. 


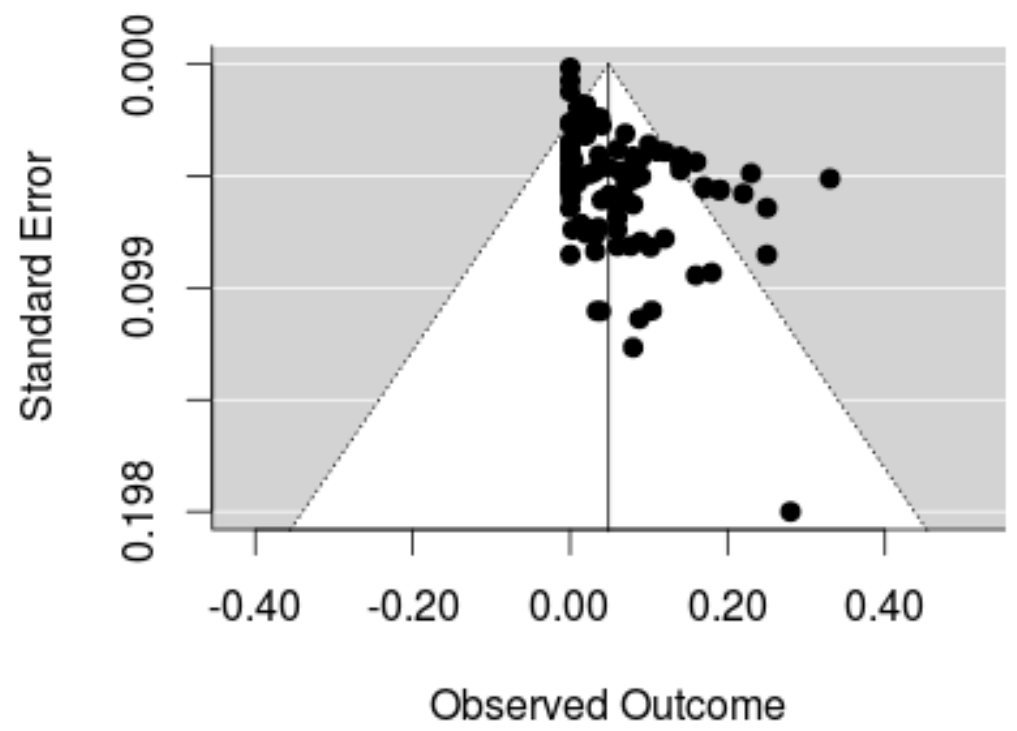

Figure 2. Funnel plot of effect sizes, showing statistically significant asymmetries across studies. 